$$
\text { DOE/EW/5700/. TI }
$$

\title{
Algorithms for a Hand-held Miniature X-ray Fluorescence Analytical Instrument
}

A Report to the Department of Energy

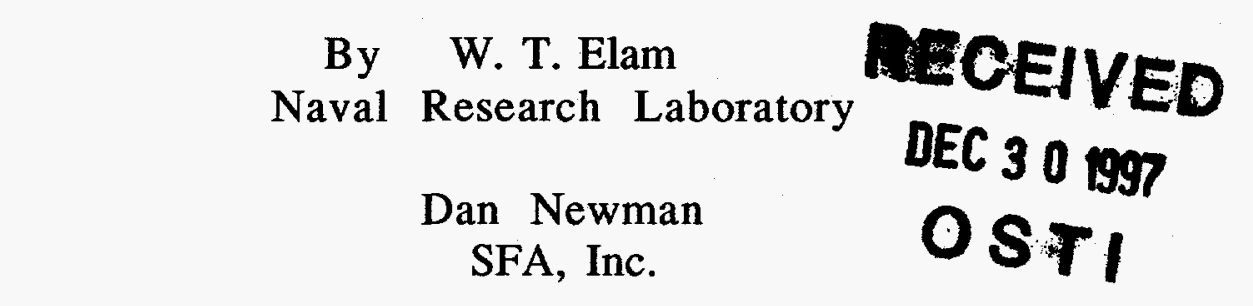

Frank Ziemba, Adrew Cheng, and Erol Yesin

Quantrad Sensor, Inc.

and Gordon A. Anderson

Pacific Northwest Laboratory

Under Interagency Agreement DE-AI01-97EW57001

PR Number 01-97EW57001.000

Delivered to:

U. S. Department of Energy

Office of Environmental Restoration and Waste Management

Attn: Eric Lightner, EM-531

Washington, DC 20585

U. S. Department of Energy

Headquarters Procurement Operations

Attn: Calvin Lee

Washington, DC 20585

U. S. Department of Energy

Office of Scientific and Technical Information

Attn: Special Assistant for Repro. and Process.

P. O. Box 62

Oak Ridge, TN 37830 


\section{DISCLAIMER}

This report was prepared as an account of work sponsored by an agency of the United States Government. Neither the United States Government nor any agency thereof, nor any of their employees, makes any warranty, express or implied, or assumes any legal liability or responsibility for the accuracy, completeness, or usefulness of any information, apparatus, product, or process disclosed, or represents that its use would not infringe privately owned rights. Reference herein to any specific commercial product, process, or service by trade name, trademark, manufacturer, or otherwise does not necessarily constitute or imply its endorsement, recommendation, or favoring by the United States Government or any agency thereof. The views and opinions of authors expressed herein do not necessarily state or reflect those of the United States Government or any agency thereof. 


\section{DISCLAIMER}

Portions of this document may be illegible electronic image products. Images are produced from the best available original document. 


\section{INTRODUCTION:}

The purpose of this joint program was to provide technical assistance with the development of a Miniature X-ray Fluorescence (XRF) Analytical Instrument. This new XRF instrument is designed to overcome the weaknesses of spectrometers commercially available at the present time.

Currently available XRF spectrometers (for a complete list see reference 1) convert spectral information to sample composition using the influence coefficients technique or the fundamental parameters method. They require either a standard sample with composition relatively close to the unknown or a detailed knowledge of the sample matrix. They also require a highly-trained operator and the results often depend on the capabilities of the operator. In addition, almost all existing field-portable, hand-held instruments use radioactive sources for excitation. Regulatory limits on such sources restrict them such that they can only provide relatively weak excitation. This limits all current hand-held XRF instruments to poor detection limits and/or long data collection times, in addition to the licensing requirements and disposal problems for radioactive sources.

The new XRF instrument was developed jointly by Quantrad Sensor, Inc., the Naval Research Laboratory (NRL), and the Department of Energy (DOE). This report describes the analysis algorithms developed by NRL for the new instrument and the software which embodies them.

\section{OBJECTIVE:}

The following tasks were performed during this program in FY97:

1. Improve fundamental parameters calculations

1.a Survey literature for best values of fundamental physical parameters needed to calculate $\mathrm{x}$-ray yields

1.b Incorporate new parameter values in fundamental parameters XRF calculations

1.c Test accuracy of fundamental parameters calculations for a wide range of sample compositions and geometries 
2. Develop fully automated analysis method for field XRF data

2.a Peak identification and assignment to elements

2.b Evaluation of available standards from library by comparison to unknown

2.c Calculation of standards from fundamental parameters when necessary

2.d Select regression model for optimal use of available standards and calculations

\section{APPROACH:}

1. The principal limitation to the fundamental parameters method of XRF analysis has been the accuracy of the atomic parameters used to calculate the $x$-ray emission. NRL developed one of the first fundamental parameters computer programs in the late 1960s and early $1970 \mathrm{~s}^{2}$. The method has remained virtually unchanged since then ${ }^{3}$. During the intervening years improved values of these parameters have become available.

1a. A complete survey of the literature was undertaken to find the latest available values of the atomic parameters used in the fundamental parameters method. The search included both the traditional, published, archival literature and online resources available over the Internet.

1b. A portion of these newer values were incorporated into the fundamental parameters program from NRL (called NRLXRF) ${ }^{2}$. A few tests of calculations with the newer values were performed and compared to the results using the older values.

1c. Calculations of the predicted XRF intensities for several alloys, similar to those found in the expected uses of the new instrument, were performed and compared to the measured XRF intensities for the same alloys. 
2. To achieve an effective and fully automated instrument requires analytical methods which convert the XRF spectrum into sample composition without operator decisions and in an adaptive manner. Algorithms were chosen to provide the best analysis available for a completely unknown sample, since such situations are often encountered in the field. Pure elements and a built-in library of physical standards are used and automatically selected by an algorithm which heavily weights those standards which are closest to the unknown in $x$-ray intensity. In addition, fundamental parameters calculations augment actual standards to achieve complete coverage of possible sample compositions.

2a. A novel, reliable, and very rapid algorithm was developed under this program to break the spectrum down into the intensities from each constituent element. The algorithm provides the $\mathrm{x}$-ray intensity, relative to the corresponding pure element, from the raw $\mathrm{XRF}$ spectrum in a single calculation step.

2b. A weighting scheme was developed to select the most appropriate standard from the built-in library for analysis of a given unknown spectrum. The weighting scheme is based on differences between the intensities of the various constituent elements in the standard and unknown. The normalization and weighting of the differences was crucial to insure selection of an appropriate standard for a wide variety of unknown samples.

2c. Fundamental parameters calculations were performed using the algorithms from the NRLXRF computer program ${ }^{2}$. These calculations were tested for accuracy in task $1 \mathrm{c}$ and the exact codes used in the tests were also used to perform the calculations for the database of coefficients used in the instrument.

2d. The regression model chosen to convert the $x$-ray intensities to sample composition was the method outlined by DeJongh ${ }^{4}$. This method takes advantage of both spectral measurements on physical standards and calculation via fundamental parameters in a natural and versatile way. It yields the best possible results when unknowns are analyzed which have compositions near the available standards but gives reasonable values for almost any unknown composition. The fundamental parameters calculations are used in a differential manner, which dramatically reduces the errors inherent in their use. 


\section{ACCOMPLISHMENTS:}

The results of the literature survey for updated values of the atomic parameters are given in References 5-20. These include new values for the elemental $x$-ray absorption coefficients 7 , fluorescence yields ${ }^{11}$, cross sections ${ }^{15}$, Coster-Kronig transition rates ${ }^{12}$, and a variety of scattering intensities (Rayleigh/elastic, anomalous, and relativistic) $16,17,18,19,20$. The principal benefit of these new values is the extension of reliable measurements of $x$-ray absorption cross sections to lower photon energies ${ }^{5-9}$. Substantial improvements in the calculation of the spectra for $x$-ray tubes has also been made (by the same group at NRL which did the original calculation for NRLXRF) ${ }^{13}$. There is, however, somewhat less new information than might be expected at first glance. In the range of $\mathrm{x}$-ray emissions by most transition metals ( 1 to $30 \mathrm{keV}$ ), the values of the $\mathrm{x}$-ray absorption coefficients are simply the values from the McMaster tables 21 of 1969 . The extension to lower energies $(10-1000 \mathrm{eV})$ can be expected to improve the fundamental parameters calculation, but only secondarily. Several other important parameter values are changed relatively little in the new references.

The ultimate test of the new values is their effect on the results of the fundamental parameters calculations of interest for use in the new instrument. The new values for $x$-ray absorption were included in the NRLXRF codes, since they were deemed to be the greatest improvement over the old values and should make a definite improvement. It was rapidly discovered that there were discrepancies between the old and new values for some parameters. Updating one set of parameters without providing accurate values for the remainder actually made the results worse. The most glaring was tiny differences in the absorption edge energies between the old and new absorption tables. Since the jump in absorption just below and just above the absorption edge in a constituent element is a crucial factor in the $\mathrm{x}$-ray fluorescence yield, this proved disastrous. The absorption is calculated by the program one eV below and one $\mathrm{eV}$ above the edge according to a table of edge energies. The new absorption coefficient tables had their edge jump values at energies different by 1 to $5 \mathrm{eV}$ from the values in the old tables. An attempt was made to extract the actual edge jump energies from the new table, but no reliable method was found during this project. It thus became impossible to get usable results with the new absorption tables. 
The improvements in calculation of spectra from $x$-ray tubes was more fruitful. The values from the new calculation code described in reference 13 were used to calculate the expected yield from the $\mathrm{x}$ ray tube used in the new instrument with excellent agreement in overall spectral shape. The calculations were also compared to very precise measurements of actual tube output in the literature 22 and agreement was found to within a few percent in all cases. Again, however, incorporating the results into the fundamental parameters calculation done by NRLXRF made little noticeable difference.

Table II in the Appendix compares the x-ray intensities calculated via fundamental parameters to the measured $x$-ray intensities for 72 alloys. The fundamental parameters calculations use only the alloy composition and the experimental measurement conditions (the $\mathrm{x}$ ray tube target and voltage plus the incident and detected beam angles). The measured values were obtained with the new XRF Analytical Instrument. Both intensities are presented as relative $\mathrm{X}$ ray intensities (RXI), which is the ratio of the intensity of the $x$-ray emission line from a given constituent element of the alloy to the intensity from a pure sample of the same element. This ratio reduces the effect of systematic errors in some of the fundamental parameters and in the measured intensities.

The good news is that the fundamental parameters calculations performed by NRLXRF were more accurate than expected on the basis of the atomic parameters which were available at the time. The fundamental parameters calculations compare very well to the measured values, usually agreeing to within $10 \%$. This is true even for the difficult case of chromium and iron in stainless steels. The calculations are almost universally about 10\% higher than he measured values. Thus, if the calculated values are used in a differential mode, where they are corrected to measured values from a physical standard, their useability should be excellent. Work on improving the fundamental parameters calculations, including both improvements to the algorithms as well as updated values of the atomic parameters, will continue at NRL.

A fully automatic spectrum analysis method must accomplish the tasks listed above: convert the spectrum from the hardware into elemental intensities, select a standard from the built-in library, calculate the coefficients necessary to relate the standard intensities and composition to the unknown intensities and composition, and use 
this information to convert the spectral intensities from the unknown to its elemental composition.

Peak assignment methods in wide use fall into three types: region of interest, peak search, and peak stripping. The region-of-interest method assumes that a fixed region of the spectrum can be integrated, perhaps with subtraction of some background, to yield the integrated intensity for a particular element. This method does not handle overlapped peaks nor does it account for multiple peaks per element. The peak search method uses a smoothed second difference to locate peaks in the spectrum and select the region of interest for peak integration. Most methods also incorporate a nonlinear least squares fitting procedure to fit overlapping peaks to an assumed shape. This procedure is the most sophisticated and requires the most computing time, but it still suffers from variations in the selection of the region of interest, which skews the fitting results, and does not incorporate multiple peaks per element. Peak stripping involves finding the largest peak in the spectrum, then subtraction of this peak from the spectrum. The process then proceeds with the second largest peak (the largest remaining peak) and so forth until all peaks are removed. This is less computationally intensive than peak searching with nonlinear fitting, but suffers badly if the assumed shape of the peaks is even slightly inaccurate.

For this project, NRL developed a new algorithm based on linear least squares fitting of the spectrum with the measured spectra of each constituent element. Using the measured spectra of the individual elements both insured that the peak shapes are correct and fits all of the peaks from a given element simultaneously. The algorithm works for overlapped peaks and treats measured backgrounds on the same basis as the peaks. It is very fast (the individual element spectra can be processed in advance) and, since it uses only linear least squares techniques, is stable; reproducible, and reliable. The algorithm is described in detail in the Appendix.

An additional feature of the algorithm is the ability to reduce the spectrum into "baskets", each of which is the sum of an arbitrary number and range of spectral channels. Using these baskets dramatically reduces the computational time and power required and makes the algorithm less sensitive to peak shape.

The algorithm has been tested with generated data including noise and easily reproduces the original spectral composition within better 
than one percent even with distorted peak widths and considerable noise. The algorithm is sensitive to the energy calibration, so input from the most recent calibration is used to sum the unknown spectrum into the baskets. The output of the algorithm is fractional intensities of each element, taking into account both alpha and beta lines and normalized to pure element intensities. These results are already calibrated and give a good first approximation to the unknown sample composition, uncorrected for matrix effects (absorption or enhancement). The computation time required to decompose an unknown spectrum via Gauss-Jordan elimination, using about 30 baskets, is only a few hundred milliseconds on an 80486 processor.

The results of tests on this algorithm are shown in Figure 1 below.

Once the spectrum has been reduced to elemental $x$-ray intensities, an appropriate standard must be chosen from the library of available standards. Since the actual composition of the unknown is not yet available, the selection must be made on the basis of a match in raw intensities. The comparison is made by calculating a weighting factor for each standard according to:

$$
W_{j}=\sum_{i}\left[f\left(Y S_{i, j}-Y U_{i}\right) / Y M_{j}\right]^{2} / N_{j}
$$

where $\quad W_{j}$ is the inverse weight for standard $j$

$j$ is the index of available standards

$i$ is the index of constituent elements

$f$ is a factor which multiplies the differences

$Y S_{i, j}$ is the intensity of element $i$ in standard $j$

$\mathrm{YU}_{\mathrm{i}}$ is the intensity of element $\mathrm{i}$ in the unknown

$\mathrm{YM}_{\mathrm{j}}$ is the maximum intensity for standard $\mathrm{j}$

$N_{j}$ is the number elements in standard $j$.

The standard with the smallest value of $\mathrm{W}_{j}$ is used. The factor $f$ is chosen to magnify small fractional differences to near unity. Differences smaller than $1 / \mathrm{f}$ will be reduced by the squaring operation while differences larger than $1 / f$ will be amplified. A judicious choice of $f$ together with normalization by the largest elemental intensity in the standard are crucial to the proper operation of this algorithm. A value of 10 for $f$ yields the best performance. The evaluation of this weighting scheme was based on the results produced by the overall process. That is, the scheme and 
values described above yielded the best agreement between measured and actual values of a list of alloys (see Table III in the Appendix).

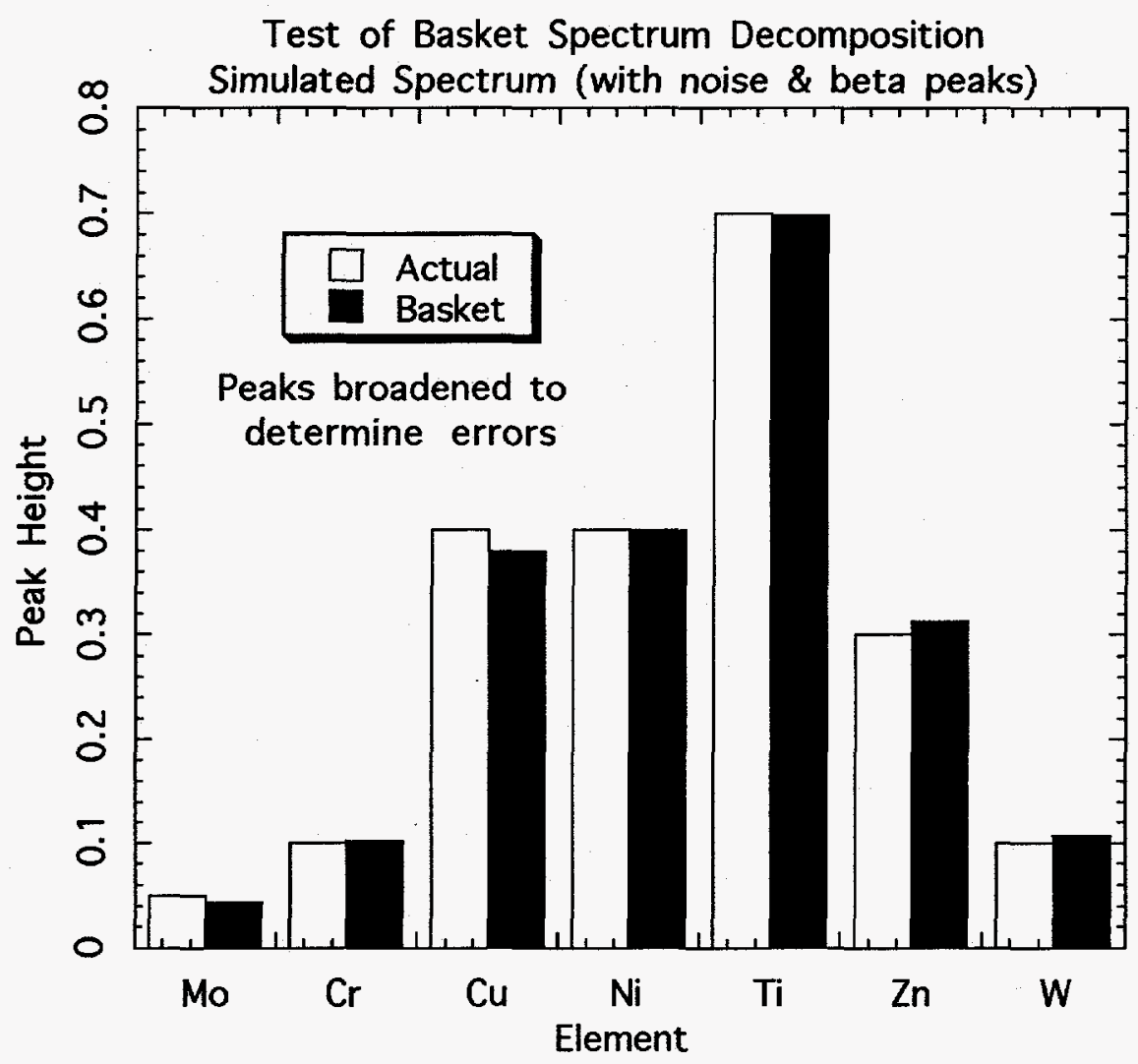

Figure 1. Results of application of the spectral decomposition algorithm to simulated XRF spectra including noise and peak broadening. The filled bars show the intensities from the decomposition algorithm applied to a simulated spectrum where noise has been added and the peaks broadened. The open bars are the actual intensities which were included in the simulated spectrum.

The fundamental parameters calculations used to augment the physical standards were based on the computer program NRLXRF, which is described in reference 2 . The program is in the public domain, but the version used in this project has had improvements incorporated for this project, including changes to run on personal computers and the incorporation of updated atomic parameters as 
described above. The details of the fundamental parameters method are beyond the scope of this report, but are covered in reference 3 and in reference 23 . The information relevant to this project has been covered in the discussion of atomic parameters above.

Conversion of the elemental intensities into composition of the unknown followed the method outlined by DeJongh ${ }^{4}$. This method is described in detail in reference 24 . The conversion of intensities into composition must take into account the effects of the matrix, such as absorption of the characteristic $x$-rays for each element and enhancement effects. The latter occur when the $x$-rays emitted by one element preferentially excite another element. Both of these effects depend on the actual composition, making the problem a set of interacting equations which must be solved via linear algebra. In general the problem is nonlinear, but all current methods assume a linear approximation is adequate. The DeJongh method is one of several "standard compensation" methods which use the differences in intensity between an unknown and a selected standard to determine the composition of the unknown relative to the composition of the standard. These methods do not attempt to determine a general calibration curve over all compositions. DeJongh's method takes advantage of the fundamental parameters method to calculate the coefficients which relate the differences in intensity to differences in composition. The method has two very strong advantages. It does not require a large number of standards to evaluate the coefficients or to generate a calibration curve over a wide range of compositions. However, it uses the fundamental parameters calculations only in a differential mode, greatly reducing its sensitivity to errors in the calculations. This method provides the best of both the accuracy of calibration standards and the wide composition range of fundamental parameters calculations. The results will be best where the unknown is close in composition to one of the available standards but will provide reasonable results over a very wide range of possible compositions. The actual algorithm and a few refinements included in the new instrument are given in the Appendix.

The results of applying the algorithms developed here to 72 alloys are given in Table III in the Appendix. The name and grade for each alloy are listed along with the measured intensities, the results of the calculated composition based on the measured intensities, and the known composition from the manufacturer for seven major elements. The agreement between the measured and given compositions are 
almost always within a few percent. The most difficult correction is the effect of iron on chromium (and vice versa) in stainless steels. The $\mathrm{x}$-ray intensity from chromium is as dependent on the amount of iron as it is on the amount of chromium.

The 72 alloys in the table are the same alloys which make up the library of physical standards for the algorithm. Each alloy was excluded from the library when it was being analyzed, forcing the choice of the closest remaining alloy (as defined by the weighting scheme described above) to be used as the reference standard.

This algorithm has been incorporated in a hand-held device for alloy analysis. The unit is about 8 by 8 inches square and 20 inches long. It weighs less than 20 pounds and can be easily operated by a single individual. The results presented here were obtained with data taken by this device. A picture of the device in shown in Figure 2 below.

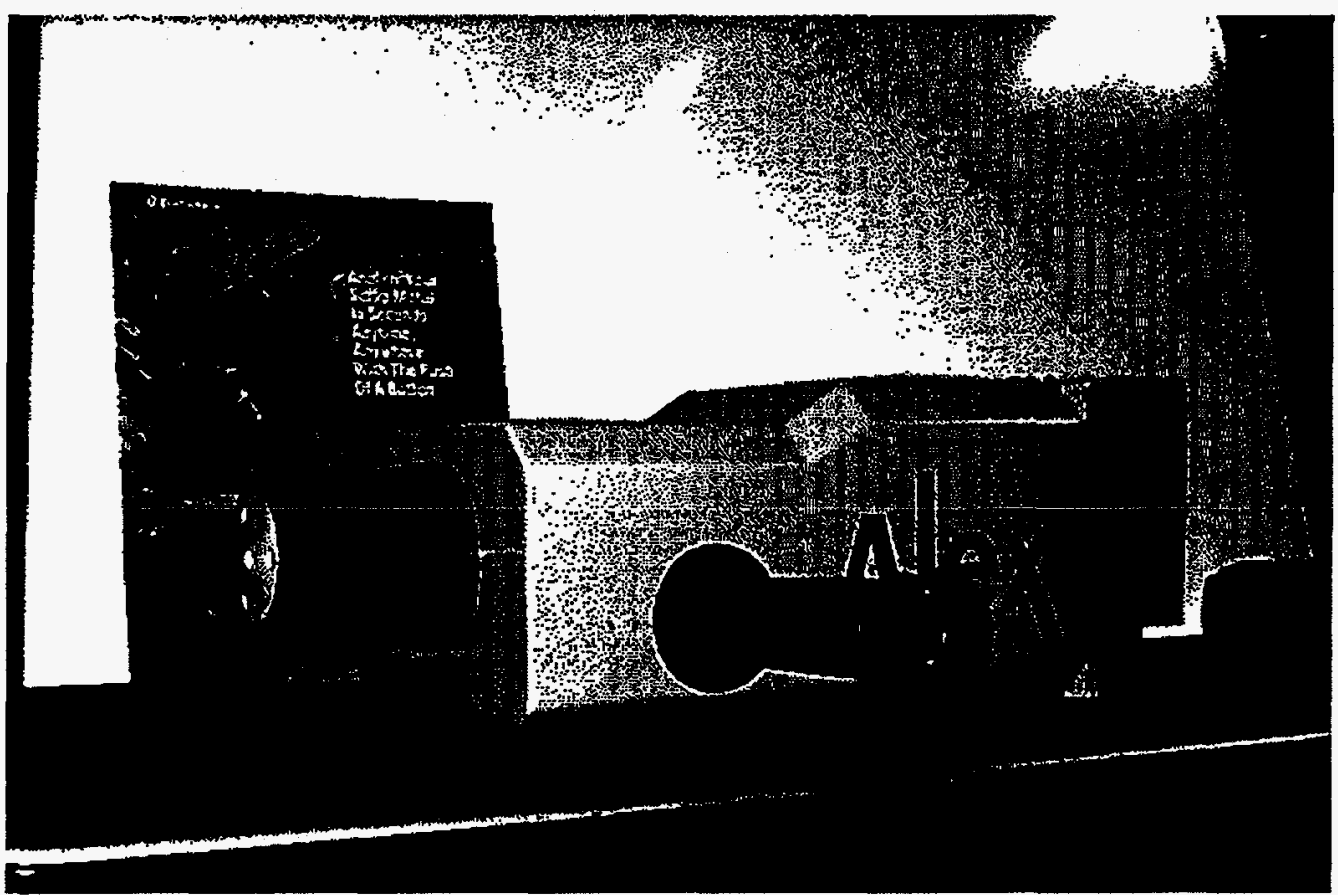

Figure 2. A photo of the hand-held Miniature Analytical X-ray Fluorescence Instrument.

\section{CONCLUSION}

A set of algorithms, including a novel linear-least-squares method of spectral decomposition, has been developed for a Miniature X-ray 
Fluorescence (XRF) Analytical Instrument. The algorithms have been tested to determine the performance, both as individual parts and collectively. The spectral decomposition algorithm uses minimal computing power and is insensitive to peak shape distortions and to noise. The conversion of $\mathrm{x}$-ray spectral intensities to elemental composition follows the method of DeJongh, which uses differential coefficients to relate the differences in $x$-ray intensity between the unknown and a physical reference standard to differences in composition. The accuracy of the fundamental parameters method used to calculate the differential coefficients is within $10 \%$ for the 72 alloys used as the library of reference standards. A careful choice of the weighting scheme used to select the standard to be used in the DeJongh method was crucial. A weighting scheme based on summing the squares of normalized differences in $\mathrm{x}$-ray intensities was developed and optimized based on performance. The complete algorithm was tested by treating each of the 72 physical standards as unknowns (and removing the respective standard from the library during its own analysis). The results confirm that the algorithms yield results within a few percent in almost all cases and are computationally very efficient. The algorithms have been incorporated into the hand-held alloy analyzer shown in Figure 2. 


\section{REFERENCES}

1. "X-ray Spectrometry Source List", Spectroscopy 10(6), 1995

2. "Versatile X-ray Analysis Program Combining Fundamental Parameters and Empirical Coefficients", J. W. Criss, L. S. Birks, and J. V. Gilfrich, Analytical Chemistry 50, 33-37 (1978).

3. Principles of Quantitative X-ray Fluorescence Analysis, R. Tertian and F. Claisse (Heyden, London, 1982), ISBN 0-85501-709-0, pp122129.

4. "X-ray Fluorescence Analysis Applying Theoretical Matrix Corrections. Stainless Steel", Willy K. DeJongh, X-ray Spectrometry 2, 151-158 (1973).

5. "A Temperature Dependent ENDF/B-VI, Release 4, Cross Section Library", D. E. Cullen, Lawrence Livermore National Laboratory Report UCRL-ID-127776, July 4, 1997.

6. "Tart 96, A coupled neutron-photon 3-D, combinatorial geometry Monte Carlo transport code", D. E. Cullen, Lawrence Livermore National Laboratory Report UCRL-ID-126455, November 22, 1996.

7. "Tables and Graphs of Photon Interaction Cross Sections from 0.1 $\mathrm{keV}$ to $100 \mathrm{MeV}$ Derived from the LLL Evaluated Nuclear Data Library," Plechaty, E. F., Cullen, D. E., and Howerton, R. J., Report UCRL-50400, Vol. 6, Rev. 2, Lawrence Livermore National Laboratory, Livermore, CA. (1978).

8. "Tables and Graphs of Photon-Interaction Cross Sections from 0.1 $\mathrm{keV}$ to $100 \mathrm{MeV}$ Derived from the LLL Evaluated-Nuclear-Data Library", Plechaty, E. F., Cullen, D. E., and Howerton, R. J., NTIS Report DE82004819 (UCRL-50400, Vol. 6, Rev. 3), November 11, 1981 (Lawrence Livermore National Laboratory, Livermore, CA).

9. "EPDL97 The Evaluated Data Library, '97 Version", D. E. Cullen, J. H. Hubbel, and L. Kissel, UCRL-50400, Vol. 6, Rev. 5, September 19, 1997 (Lawrence Livermore National Laboratory, Livermore, CA).

10. "A Suite of Programs for Calculating X-ray Absorption, Reflection and Diffraction Performance for a Variety of Materials at Arbitrary 
Wavelengths", S. Brennan and P. L. Cowan, Rev. Sci. Instrum., 63, 850 (1992).

11. "Atomic Radiative and Radiationless Yields for K and L Shells", M. O. Krause, J. Phys. Chem. Ref. Data 8, 307-327 (1979). Also "Natural Widths of Atomic K and L Levels, K $\alpha$ X-ray Lines and Several KLL Auger Lines", M. O. Krause and J. H. Oliver, J. Phys. Chem. Ref. Data 8, 329-338 (1979)

12. "Atomic L-Shell Coster-Kronig, Auger, and Radiative Rates and Fluorescence Yields for Na-Th", E. J. McGuire, Phys. Rev. A3, 587-593 (1971).

13. "Calculation of Spectra from Electron-Impact X-ray Sources", D. B. Brown and D. J. Nagel, in Low Energy X-ray Diagnostics - 1981 Ed. D. T. Atwood (AIP, New York, 1981).

14. A. P. Hitchcock and D. C. Mancini, in Journal of Electron Spectroscopy and Related Phenomena, Vol. 67, No. 1 (1994).

15. "Low-Energy X-ray Interaction Coefficients: Photoabsorption, Scattering, and Reflection E $=30-30,000 \mathrm{eV}, \mathrm{Z}=1-92 ", \mathrm{~B}$. L. Henke, E. M. Gullikson, and J. C. Davis, in Atomic Data and Nuclear Data Tables 54, No. 2 (1993).

16. "Elastic Photon-Atom Scattering", Lynn Kissel and Paul M. Bergstrom, Jr., http://wwwphys.1lnl.gov/V_Div/scattering/elastic.html

17. "Validity of Form-Factor, Modified-Form-Factor and AnomalousScattering-Factor Approximations in Elastic Scattering Calculations," by Lynn Kissel, B. Zhou, S. C. Roy, S. K. Sen Gupta and R. H. Pratt, Acta Crystallographica A51, 271-288 (1995).

18. "New Relativistic S-Matrix Results for Scattering - Beyond the Usual Anomalous Factors/Beyond Impulse Approximation," R. H. Pratt, Lynn Kissel and P. M. Bergstrom, Jr., in Resonant Anomalous XRay Scattering, ed. G. Materlik, C. J. Sparks and K. Fischer (NorthHolland: Amsterdam, 1994).

19. "Elastic Scattering of Gamma-Rays and X-Rays by Atoms," P. P. Kane, Lynn Kissel, R. H. Pratt and S. C. Roy, Physics Reports 140, 75159 (1986). 
20. "Rayleigh Scattering - Elastic Photon Scattering by Bound Electrons," Lynn Kissel and R. H. Pratt, in Atomic Inner-Shell Physics, ed. Bernd Crasemann (Plenum Publishing: New York, 1985).

21. "Compiliation of X-ray Cross Sections", W. H. McMaster, N. Kerr Del Grande, J. H. Mallett, and J. H. Hubbell, UCRL-50174, Sec. II, Rev. 1 Lawrence Livermore National Laboratory, Livermore, CA (1969).

22. "Spectral Distribution of X-ray Tubes for Quantitative X-ray Fluorescence Analysis", J. V. Gilfrich and L. S. Birks, Analytical Chemistry 40, 1077-1080 (1968).

23. "Calculation Methods for Fluorescent X-ray Spectrometry, Empirical Coefficients vs. Fundamental Parameters", J. W. Criss and L. S. Birks, Analytical Chemistry 40, 1080-1086 (1968).

24. Reference 3, pp164-167.

\section{APPENDIX I.}

Algorithm for Spectral Decomposition.

The XRF spectrum from the instrument is viewed as a superposition of one or more pure element spectra, which are known, plus a background with known profile and some amount of noise and other distortion. The elemental intensities in this spectrum can be obtained from the coefficients of superposition of the pure element spectra. Since the instrument spectrum contains noise and distortion, we must apply a least squares technique to the data to extract the elemental intensities.

The background is treated the same as the component spectra. If the background can be approximated as a polynomial, then each term of the polynomial can be calculated as a separate component and the algorithm will adjust the coefficients as necessary.

This algorithm assumes that each pure element spectrum profile is somewhat linearly independent. That is for any pair of pure element spectra (or background profiles) $M(j)$ and $N(j)$ consisting of $n$ sampled data points: 


$$
\operatorname{Sum}(|M(j)-a * N(j)|, j=1,2, \ldots, n)>>0 \text { for all values of } a \text {. }
$$

Let $L(i, j)$ be the spectrum of the $i^{\prime}$ th pure element (or background) with $j$ the index for the $j$ th sample as a function of energy. There are $\mathrm{m}$ different pure element or background profiles. These spectra are assumed known a priori and are sampled with the same energy grid as the unknown spectrum. The unknown spectrum is approximately equal to the weighted sum of the L's with coefficients c(i) plus noise or other distortion. Let $S(j)$ be the unknown spectrum.

$$
S(j) \sim=\operatorname{Sum}(c(i) * L(i, j), i=1, \ldots, m)
$$

We wish to minimize the sum of the squares of the differences, $d(j)$ (defined below), with respect to the coefficients, c(i).

$$
d(j)=S(j)-\operatorname{Sum}(c(i) * L(i, j), i=1, \ldots, m) .
$$

To cast the problem as a least squares minimization, we want to minimize

$$
G=\operatorname{Sum}\left(d(j)^{2}, j=1, \ldots, n\right) \text { with respect to each } c(i) .
$$

To do this, we set the partial derivatives of $G$ wrt the $c(i)$ equal to zero and solve for the $c(i)$. This gives:

$$
\frac{\partial G}{\partial c_{i}}=2 \sum d_{j} \frac{\partial d_{j}}{\partial c_{i}}
$$

Solving for the partial derivative in terms of the unknown and pure element spectra gives:

$$
\frac{\partial G}{\partial c_{i}}=2 \sum_{j}\left(L_{i, j}\right)\left[S_{j}-\sum_{k} c_{k} L_{k, j}\right]
$$

This can be reformulated as a matrix eqn as follows:

Let $T(i, j)=\operatorname{Sum}(L(i, k) * L(j, k), k=0,1,2, \ldots, n-1)$

and $U(i)=\operatorname{Sum}(S(j) * L(i, j), j=0,1, \ldots, n-1)$ then 


$$
\sum_{j} T_{i, j} c_{j}=U_{i}
$$

Since the matrix contains values that can be calculated purely from the already known spectral profiles, it need only be calculated once and inverted, or it can be used repeatedly in a Gauss-Jordan elimination on an augmented matrix.

A modification of this algorithm uses variable sized bins, referred to here as baskets. Each spectrum from the multichannel analyzer is summed over a range of channels to form a basket. In areas where any spectral profile has a major feature, small baskets can be used. In regions where no features are expected, a basket can span many channels This can be used to reduce the amount of data processing and increase the insensitivity to distortion of lines, etc. It is particularly important to chose the baskets such that a resolution is high where lines may overlap. The list of basket boundaries is given in Table $\mathbf{I}$ below.

Since the measured pure element spectra contain noise, generated spectra are used in computing the matrices. The generated pure element spectra are comprised of Gaussian lineshapes fit and summed to match the measured pure element spectra. This process was semi-automated with final comparison and adjustment by hand to insure that the generated spectra matched the measured pure element spectra. The background profiles were computed by repeatedly smoothing the measured background spectrum.

Table I. Basket definitions used to sum spectra:

\begin{tabular}{|l|l|l|}
\hline $\begin{array}{l}\text { Basket } \\
\text { number }\end{array}$ & $\begin{array}{l}\text { Start } \\
\text { Energy }\end{array}$ & $\begin{array}{l}\text { End } \\
\text { Energy }\end{array}$ \\
\hline 1 & 1.000 & 2.519 \\
\hline 2 & 2.569 & 3.779 \\
\hline 3 & 3.829 & 4.681 \\
\hline 4 & 4.731 & 5.136 \\
\hline 5 & 5.186 & 5.626 \\
\hline 6 & 5.676 & 6.121 \\
\hline 7 & 6.171 & 6.641 \\
\hline 8 & 6.691 & 7.183 \\
\hline 9 & 7.233 & 7.740 \\
\hline
\end{tabular}




\begin{tabular}{|l|l|l|}
\hline 10 & 7.790 & 8.234 \\
\hline 11 & 8.284 & 8.388 \\
\hline 12 & 8.438 & 8.600 \\
\hline 13 & 8.650 & 8.860 \\
\hline 14 & 8.910 & 9.095 \\
\hline 15 & 9.145 & 9.360 \\
\hline 16 & 9.410 & 9.540 \\
\hline 17 & 9.590 & 10.050 \\
\hline 18 & 10.100 & 10.346 \\
\hline 19 & 10.396 & 11.050 \\
\hline 20 & 11.100 & 12.016 \\
\hline 21 & 12.066 & 15.720 \\
\hline 22 & 15.770 & 17.014 \\
\hline 23 & 17.064 & 18.078 \\
\hline 24 & 18.128 & 19.137 \\
\hline 25 & 19.187 & 20.041 \\
\hline 26 & 20.091 & 21.441 \\
\hline 27 & 21.491 & 22.697 \\
\hline 28 & 22.747 & 24.467 \\
\hline 29 & 24.517 & 25.367 \\
\hline & & \\
\hline
\end{tabular}

Table II. Table of results for fundamental parameters calculation of $\mathrm{x}$-ray fluorescence intensity compared to measured intensity for selected elements in 72 alloys. The alloy name and composition are given, followed by the calculated and measured $\mathrm{x}$-ray intensities. Calculations were performed by the NRLXRF computer code. XG is the known composition, $\mathrm{YC}$ the calculated intensity, and $\mathrm{YM}$ the measured intensity.

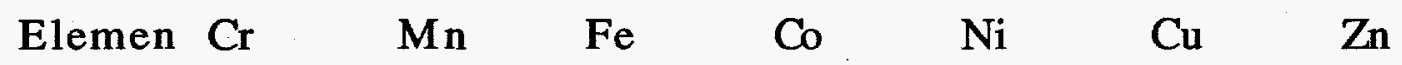
ts:

BS44 C- $\quad$.5Mo 4419

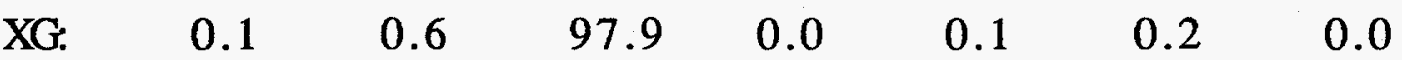

$\begin{array}{lllllllll}\text { YC } & & 0.0021 & 0.0060 & 0.9772 & 0.0000 & 0.0005 & 0.0007 & 0.0000\end{array}$

$\begin{array}{llllllll}\text { YM: } & 0.0116 & 0.0180 & 0.9946 & 0.0000 & 0.0028 & 0.0000 & 0.0000\end{array}$

BS45A $1.25 \mathrm{Cr}-.5 \mathrm{Mo} \quad \mathrm{F}-1$

$\begin{array}{llllllll}\text { XG: } & 1.2 & 0.5 & 96.6 & 0.0 & 0.2 & 0.2 & 0.0\end{array}$

YC. $\quad \begin{array}{llllllll} & 0.0223 & 0.0046 & 0.9411 & 0.0001 & 0.0005 & 0.0007 & 0.0000\end{array}$

YM: $\quad \begin{array}{llllllll}0.0255 & 0.0166 & 0.9115 & 0.0058 & 0.0000 & 0.0000 & 0.0000\end{array}$ 
$\begin{array}{llllllll}\text { BS46A } & 2.25 \mathrm{Cr}-1 \mathrm{Mo} & \mathrm{F}-22 & & & & \\ \text { XG: } & 2.4 & 0.6 & 95.4 & 0.0 & 0.2 & 0.1 & 0.0 \\ \text { YC } & 0.0434 & 0.0054 & 0.8931 & 0.0001 & 0.0007 & 0.0005 & 0.0000 \\ \text { YM: } & 0.0651 & 0.0314 & 0.8920 & 0.0027 & 0.0057 & 0.0000 & 0.0001 \\ \text { BS47A } & 5 \mathrm{Cr}- & .5 \mathrm{Mo} & \mathrm{F}-5 & & & & \\ \text { XG: } & 4.2 & 0.4 & 94.1 & 0.0 & 0.1 & 0.1 & 0.0 \\ \text { YC: } & 0.0755 & 0.0044 & 0.8477 & 0.0001 & 0.0004 & 0.0004 & 0.0000 \\ \text { YM: } & 0.0896 & 0.0232 & 0.8830 & 0.0000 & 0.0007 & -.0005 & 0.0000\end{array}$ BS48A $9 \mathrm{Cr}-1 \mathrm{Mo} \quad$ F-9

$\begin{array}{llllllll}\text { XG. } & 8.8 & 0.4 & 88.5 & 0.0 & 0.3 & 0.1 & 0.0\end{array}$

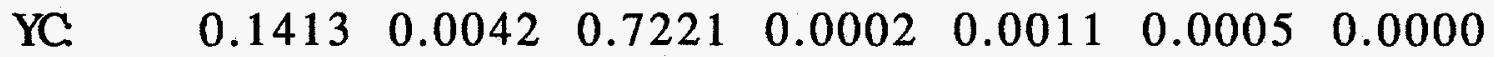

$\begin{array}{llllllll}\text { YM: } & 0.1551 & 0.0205 & 0.6849 & 0.0000 & 0.0052 & 0.0000 & 0.0000\end{array}$

BS150 182FM

$\begin{array}{llllllll}\text { XG: } & 18.6 & 1.7 & 76.5 & 0.0 & 0.2 & 0.0 & 0.0\end{array}$

YC. $\quad \begin{array}{llllllll}0.2520 & 0.0162 & 0.5180 & 0.0002 & 0.0007 & 0.0002 & 0.0000\end{array}$

$\begin{array}{lllllllll}\text { YM: } & 0.2706 & 0.0129 & 0.4591 & 0.0000 & -.0002 & -.0002 & 0.0000\end{array}$

BS151 $416 \quad \mathrm{Se}$

$\begin{array}{llllllll}\text { XG. } & 13.2 & 0.4 & 85.1 & 0.0 & 0.2 & 0.1 & 0.0\end{array}$

$\begin{array}{lllllllll}\text { YC. } & & 0.2033 & 0.0040 & 0.6401 & 0.0002 & 0.0009 & 0.0004 & 0.0000\end{array}$

YM: $\quad \begin{array}{lllllllll}0.2140 & 0.0143 & 0.6033 & 0.0033 & 0.0000 & -.0004 & 0.0000\end{array}$

BS410A 410

$\begin{array}{llllllll}\text { XG: } & 13.2 & 0.5 & 85.3 & 0.0 & 0.2 & 0.0 & 0.0\end{array}$

YC. $\quad \begin{array}{llllllll}0.2022 & 0.0045 & 0.6406 & 0.0000 & 0.0009 & 0.0001 & 0.0000\end{array}$

YM: $\quad \begin{array}{llllllll}0.2223 & 0.0077 & 0.5690 & 0.0084 & 0.0007 & 0.0000 & 0.0000\end{array}$

BS90F 416

$\begin{array}{llllllll}\text { XG. } & 13.0 & 0.5 & 84.7 & 0.0 & 0.3 & 0.1 & 0.0\end{array}$

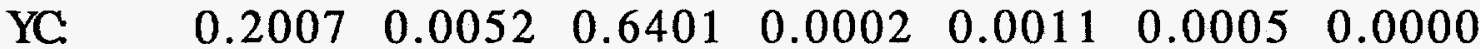

YM: $\quad \begin{array}{llllllll}0.2193 & 0.0234 & 0.5944 & 0.0000 & 0.0005 & 0.0000 & 0.0000\end{array}$

BS95A 450

$\begin{array}{llllllll}\text { XG: } & 14.7 & 0.6 & 74.8 & 0.1 & 6.4 & 1.5 & 0.0\end{array}$

$\begin{array}{lllllllll}\text { YC. } & & 0.2036 & 0.0056 & 0.5516 & 0.0007 & 0.0252 & 0.0063 & 0.0000\end{array}$

$\begin{array}{lllllllll}\text { YM: } & 0.2327 & 0.0117 & 0.5078 & 0.0000 & 0.0183 & 0.0027 & 0.0000\end{array}$

BS97 - 422

$\begin{array}{llllllll}\text { XG: } & 11.8 & 0.7 & 83.7 & 0.0 & 0.8 & 0.1 & 0.0\end{array}$

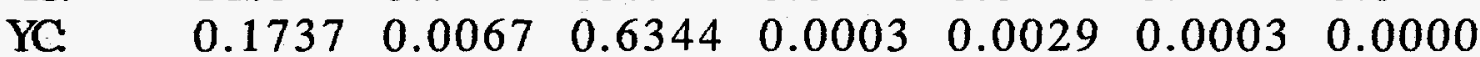

YM: $\quad \begin{array}{llllllll}0.1777 & 0.0204 & 0.6076 & 0.0050 & 0.0036 & 0.0000 & 0.0000\end{array}$

BS98 420

$\begin{array}{llllllll}\text { XG: } & 13.3 & 0.5 & 84.6 & 0.0 & 0.2 & 0.1 & 0.0\end{array}$

YC: $\quad \begin{array}{llllllll}0.2060 & 0.0047 & 0.6362 & 0.0002 & 0.0008 & 0.0004 & 0.0000\end{array}$

$\begin{array}{llllllll}\text { YM: } & 0.2254 & 0.0121 & 0.5637 & 0.0033 & 0.0000 & 0.0000 & 0.0000\end{array}$

BS152 420F

$\begin{array}{llllllll}\text { XG. } & 13.4 & 0.4 & 84.8 & 0.0 & 0.1 & 0.1 & 0.0\end{array}$

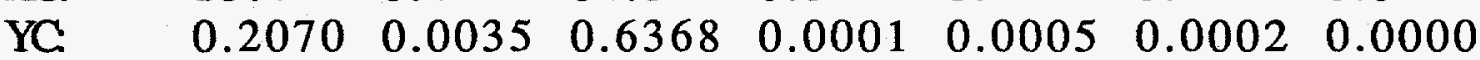




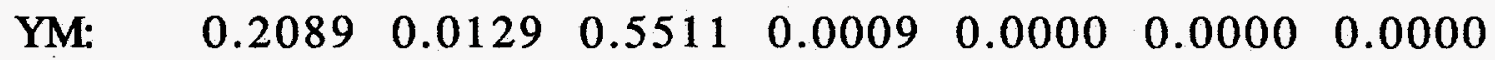
BS91E 430

$\begin{array}{llllllll}\text { XG: } & 16.6 & 0.4 & 82.0 & 0.0 & 0.2 & 0.1 & 0.0 \\ \text { YC: } & 0.2439 & 0.0041 & 0.5796 & 0.0002 & 0.0006 & 0.0002 & 0.0000 \\ \text { YM: } & 0.2424 & 0.0114 & 0.5208 & 0.0024 & 0.0000 & -.0003 & 0.0000\end{array}$ BS153 430F

$\begin{array}{llllllll}\text { XG. } & 17.4 & 0.4 & 80.8 & 0.0 & 0.1 & 0.1 & 0.0\end{array}$

YC $\quad \begin{array}{llllllll}0.2518 & 0.0040 & 0.5636 & 0.0001 & 0.0005 & 0.0002 & 0.0000\end{array}$

$\begin{array}{lllllllll}\text { YM: } & & 0.2403 & 0.0151 & 0.5050 & 0.0000 & 0.0000 & -.0003 & 0.0000\end{array}$ BS92B 431

$\begin{array}{llllllll}\text { XG. } & 15.9 & 0.4 & 80.4 & 0.0 & 2.1 & 0.1 & 0.0\end{array}$

$\begin{array}{lllllllll}\text { YC. } & \quad 0.2322 & 0.0041 & 0.5774 & 0.0003 & 0.0080 & 0.0005 & 0.0000\end{array}$

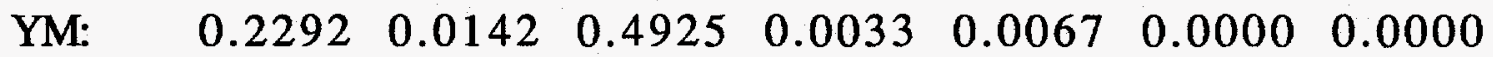

BS93E 440C

$\begin{array}{llllllll}\text { XG: } & 17.3 & 0.5 & 78.8 & 0.0 & 0.4 & 0.1 & 0.0\end{array}$

$\begin{array}{lllllllll}\text { YC. } & & 0.2499 & 0.0051 & 0.5521 & 0.0004 & 0.0013 & 0.0005 & 0.0000\end{array}$

$\begin{array}{lllllllll}\text { YM: } & 0.2578 & 0.0079 & 0.5006 & 0.0000 & 0.0009 & 0.0000 & 0.0000\end{array}$

BS155 440F

$\begin{array}{llllllll}\text { XG. } & 16.6 & 0.4 & 80.7 & 0.0 & 0.1 & 0.0 & 0.0\end{array}$

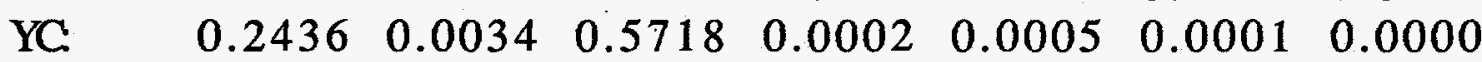

$\begin{array}{llllllll}\text { YM: } & 0.2399 & 0.0122 & 0.5168 & 0.0000 & 0.0000 & 0.0000 & 0.0000\end{array}$

BS156 440F Se

$\begin{array}{llllllll}\text { XG. } & 16.9 & 1.1 & 79.1 & 0.0 & 0.4 & 0.1 & 0.0\end{array}$

$\begin{array}{lllllllll}\text { YC. } & \quad & 0.2437 & 0.0112 & 0.5587 & 0.0004 & 0.0013 & 0.0004 & 0.0000\end{array}$

$\begin{array}{lllllllll}\text { YM: } & \quad & 0.2575 & 0.0256 & 0.5292 & 0.0000 & 0.0000 & 0.0001 & 0.0000\end{array}$

BS94C 446

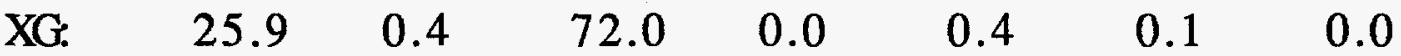

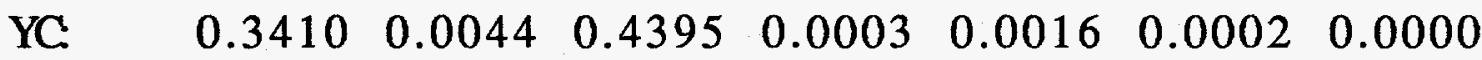

$\begin{array}{lllllllll}\text { YM: } & \quad & 0.3645 & 0.0027 & 0.3891 & 0.0000 & 0.0017 & 0.0000 & 0.0000\end{array}$

BS825A Incoloy 825

$\begin{array}{llllllll}\text { XG: } & 21.4 & 0.6 & 30.2 & 0.2 & 39.8 & 2.3 & 0.0\end{array}$

YC: $\quad \begin{array}{lllllllll}0.2241 & 0.0062 & 0.2239 & 0.0017 & 0.2126 & 0.0132 & 0.0000\end{array}$

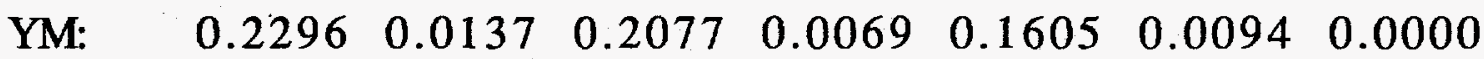

BS96A 455

$\begin{array}{llllllll}\text { XG. } & 11.6 & 0.0 & 76.2 & 0.0 & 8.4 & 2.1 & 0.0\end{array}$

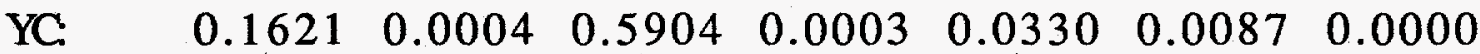

$\begin{array}{llllllll}\text { YM: } & 0.1699 & 0.0064 & 0.5433 & 0.0026 & 0.0237 & 0.0061 & 0.0000\end{array}$

BS203MN 203

$\begin{array}{llllllll}\text { XG. } & 16.8 & 6.0 & 68.7 & 0.1 & 5.5 & 1.9 & 0.0\end{array}$

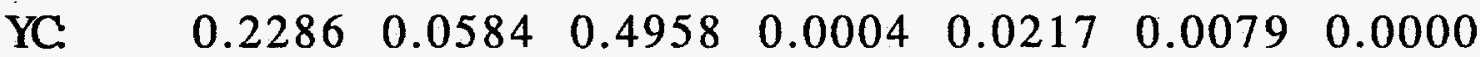

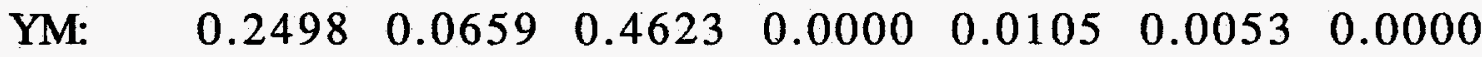

BS80F 303

$\begin{array}{llllllll}\text { XG. } & 17.1 & 1.8 & 70.2 & 0.2 & 8.6 & 0.4 & 0.0\end{array}$ 


$\begin{array}{llllllll}\text { YC: } & 0.2325 & 0.0172 & 0.5033 & 0.0012 & 0.0342 & 0.0017 & 0.0000 \\ \text { YM: } & 0.2410 & 0.0157 & 0.4540 & 0.0000 & 0.0259 & 0.0013 & 0.0000 \\ \text { BSCA304 } & 304 & & & & & & \\ \text { XG: } & 18.3 & 1.1 & 70.1 & 0.2 & 8.6 & 0.3 & 0.0 \\ \text { YC: } & 0.2465 & 0.0104 & 0.4915 & 0.0015 & 0.0341 & 0.0014 & 0.0000 \\ \text { YM: } & 0.2601 & 0.0102 & 0.4544 & 0.0014 & 0.0182 & 0.0038 & 0.0000 \\ \text { BS81G } & 304 \mathrm{~L} & & & & & & \\ \text { XG: } & 18.6 & 1.7 & 68.9 & 0.3 & 8.2 & 0.5 & 0.0 \\ \text { YC: } & 0.2473 & 0.0164 & 0.4791 & 0.0022 & 0.0326 & 0.0023 & 0.0000 \\ \text { YM: } & 0.2435 & 0.0212 & 0.4250 & 0.0049 & 0.0251 & 0.0022 & 0.0000 \\ \text { BS82D } & 309 & & & & & & \\ \text { XG: } & 22.4 & 1.9 & 60.3 & 0.0 & 14.1 & 0.2 & 0.0 \\ \text { YC: } & 0.2813 & 0.0182 & 0.4032 & 0.0003 & 0.0586 & 0.0007 & 0.0000 \\ \text { YM: } & 0.3100 & 0.0252 & 0.3609 & 0.0054 & 0.0485 & 0.0002 & 0.0000 \\ \text { BS83H } & 310 & & & & & & \\ \text { XG: } & 24.2 & 1.5 & 52.6 & 0.2 & 20.0 & 0.2 & 0.0 \\ \text { YC: } & 0.2924 & 0.0151 & 0.3498 & 0.0016 & 0.0874 & 0.0007 & 0.0000 \\ \text { YM: } & 0.3271 & 0.0130 & 0.2949 & 0.0042 & 0.0619 & 0.0000 & 0.0000 \\ \text { BS316B } & 316 & & & & & & \end{array}$

BS316B 316

$\begin{array}{llllllll}\text { XG: } & 16.2 & 1.3 & 69.3 & 0.2 & 10.1 & 0.4 & 0.0 \\ \text { YC: } & 0.2115 & 0.0121 & 0.4985 & 0.0014 & 0.0406 & 0.0015 & 0.0000 \\ \text { YM: } & 0.2289 & 0.0217 & 0.4596 & 0.0000 & 0.0287 & 0.0010 & 0.0000\end{array}$

BS84J $316 \mathrm{~L}$

$\begin{array}{llllllll}\text { XG: } & 17.1 & 1.5 & 67.4 & 0.2 & 10.3 & 0.5 & 0.0\end{array}$

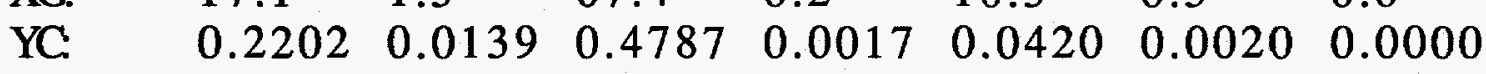

$\begin{array}{lllllllll}\text { YM: } & 0.2307 & 0.0221 & 0.4460 & 0.0074 & 0.0329 & 0.0008 & 0.0000\end{array}$

BS317L $317 \mathrm{~L}$

$\begin{array}{llllllll}\text { XG. } & 18.2 & 1.2 & 62.8 & 0.1 & 13.5 & 0.2 & 0.0\end{array}$

YC: $\quad \begin{array}{llllllll}0.2222 & 0.0110 & 0.4394 & 0.0010 & 0.0565 & 0.0010 & 0.0000\end{array}$

YM: $\quad \begin{array}{lllllllll}0.2246 & 0.0218 & 0.3899 & 0.0000 & 0.0429 & -.0001 & 0.0000\end{array}$

BS321A 321

$\begin{array}{llllllll}\text { XG: } & 17.2 & 1.2 & 70.3 & 0.2 & 9.4 & 0.3 & 0.0\end{array}$

$\begin{array}{lllllllll}\text { YC: } & \quad & 0.2297 & 0.0118 & 0.4995 & 0.0011 & 0.0373 & 0.0012 & 0.0000\end{array}$

$\begin{array}{llllllll}\text { YM: } & 0.2184 & 0.0225 & 0.4415 & 0.0013 & 0.0237 & 0.0019 & 0.0000\end{array}$

BS86E 330

$\begin{array}{llllllll}\text { XG. } & 18.5 & 1.4 & 42.7 & 0.1 & 35.3 & 0.2 & 0.0\end{array}$

$\begin{array}{lllllllll}\text { YC } & & 0.2203 & 0.0149 & 0.3304 & 0.0008 & 0.1721 & 0.0011 & 0.0000\end{array}$

$\begin{array}{lllllllll}\text { YM: } & 0.2204 & 0.0171 & 0.3011 & 0.0036 & 0.1263 & 0.0044 & 0.0000\end{array}$

BS347A 347

$\begin{array}{llllllll}\text { XG. } & 17.4 & 1.5 & 69.6 & 0.1 & 9.2 & 0.3 & 0.0\end{array}$

YC. $\quad \begin{array}{llllllll}0.2317 & 0.0145 & 0.4934 & 0.0004 & 0.0367 & 0.0013 & 0.0000\end{array}$

YM: $\quad \begin{array}{lllllllll}0.2471 & 0.0226 & 0.4574 & 0.0000 & 0.0268 & -.0007 & 0.0000\end{array}$ BS192 17-7PH 
$\mathrm{XG}$

$16.4 \quad 0.8$

0.8

72.6

0.1

7.1

0.4

0.0

YC $\quad 0.2277 \quad 0.0082$

$\begin{array}{ll}0.5250 & 0.0008\end{array}$

0.0281

$\begin{array}{ll}0.0017 & 0.0000\end{array}$

YM:

$\begin{array}{lll}0.2301 & 0.0074\end{array}$

$\begin{array}{lll}0.4545 & 0.0038\end{array}$

0.0172

$0.0023 \quad 0.0000$

BS318 2205

XG. $\quad 22.3$

$1.4 \quad 66.4$

0.1

5.6

0.2

0.0

YC.

0.2717

0.0130

0.4258

0.0007

0.0224

0.0007

0.0000

YM:

0.30320 .0160

0.39890 .0000

0.0221

$0.0000 \quad 0.0000$

BS88G 17-4PH

$\mathrm{XG}$.

15.7

$\begin{array}{ll}0.4 & 74.4\end{array}$

0.2185

0.0042

0.1

4.3

4.0

YC.

$0.2204 \quad 0.0094$

0.5433

0.0005

0.0168

0.0166

0.0

YM:

BS185A 15-5PH

$\begin{array}{lll}\text { XG. } & 14.5 & 0.5\end{array}$

YC $\quad 0.2044$

YM:

0.2235

0.0048

76.0

0.0

0.0130

0.0097

0.0000

0.0000

BS263 Alloy 263

XG:

19.8

0.4

0.5656

0.0002

4.4

3.4

0.0

YC.

0.2077

0.0045

0.5

0.0

0.0173

0.0142

0.0000

YM:

$\begin{array}{lll}0.2130 & 0.0000\end{array}$

$\begin{array}{ll}0.0040 & 0.1357\end{array}$

0.0090

0.0127

0.0000

BS189 N08367

XG:

20.6

0.3

0.0079

0.1219

50.3

0.0

0.0

YC:

0.2195

0.0024

$\begin{array}{ll}47.8 & 0.0\end{array}$

0.3840

0.0002

0.0000

0.3441

0.0000

0.0000

YM:

0.2401

0.0061

0.3275

0.0003

23.8

0.6

0.0

BS179A Alloy 255

XG: $\quad 25.5 \quad 1.0$

0.2941

0.0040

0.1100

$\begin{array}{lll}0.0030 & 0.0000\end{array}$

0.0873

0.0024

0.0000

$\begin{array}{lll}61.1 & 0.6 & 5.8\end{array}$

1.9

0.0

YC. $\quad 0.2988$

0.0098

$\begin{array}{ll}0.3768 & 0.0039\end{array}$

0.0238

0.0084

0.0000

YM:

0.3132

0.0083

BS184A PH13-8 Mo

$\begin{array}{llll}\text { XG. } & 12.7 & 0.1\end{array}$

YC $\quad 0.1756 \quad 0.0006$

$\begin{array}{ll}75.4 & 0.0\end{array}$

0.0166

$\begin{array}{lll}0.0051 & 0.0000\end{array}$

YM:

0.1700

0.0134

0.5755

8.3

0.0

0.0

BS183 Greek Ascoloy

XG: $\quad 12.8 \quad 0.4$

81.0

0.0003

0.0331

$0.0002 \quad 0.0000$

0.5000

0.0012

0.0232

0.0001

0.0000

YC. $\quad 0.1781 \quad 0.0040$

$\begin{array}{lll}0.5989 & 0.0002\end{array}$

2.0

0.1

0.0

YM:

0.1751

0.0117

0.5210

0.0000

0.0076

$0.0003 \quad 0.0000$

BS186A Invar 36

XG.

0.2

0.7

$\begin{array}{ll}63.0 & 0.0\end{array}$

0.0021

0.0000

0.0000

YC: $\quad \begin{array}{llll}0.0024 & 0.0074 & 0.6885\end{array}$

0.0003

35.9

0.0

0.0

YM:

0.0103

$\begin{array}{lll}0.0169 & 0.7479\end{array}$

0.0047

0.1651

0.0001

0.0000

0.1346

0.0009

0.0000

BS187A Carp. 20Cb3

$\begin{array}{lllll}\text { XG: } & 19.8 & 0.5 & 40.2 & 0.3\end{array}$

YC: $\quad 0.2196$

$\begin{array}{lll}0.0052 & 0.2984 & 0.0023\end{array}$

33.1

3.1

0.0

YM:

0.2632

0.0051

0.2762

0.1637

0.0163

0.0000

0.0093

0.1374

0.0122

0.0000 
BS188A A-286

$\begin{array}{llllllll}\text { XG: } & 14.0 & 0.1 & 56.9 & 0.2 & 24.6 & 0.1 & 0.0 \\ \text { YC: } & 0.1654 & 0.0013 & 0.4326 & 0.0014 & 0.1094 & 0.0005 & 0.0000 \\ \text { YM: } & 0.1746 & 0.0037 & 0.3953 & 0.0025 & 0.0842 & 0.0008 & 0.0000 \\ \text { BS190 } & \text { Nitronic } & 40 & & & & & \\ \text { XG: } & 19.6 & 9.7 & 62.8 & 0.0 & 6.7 & 0.1 & 0.0 \\ \text { YC: } & 0.2559 & 0.0945 & 0.4331 & 0.0003 & 0.0266 & 0.0003 & 0.0000 \\ \text { YM: } & 0.2785 & 0.1006 & 0.3876 & 0.0000 & 0.0196 & 0.0000 & 0.0000\end{array}$

BS180A Nitronic 50

YC: $\quad 0.2528 \quad 0.0479$

$\begin{array}{ll}57.4 & 0.0\end{array}$

13.2

0.1

0.0

YM:

0.26840 .0486

$\begin{array}{ll}0.3861 & 0.0003\end{array}$

0.0551

0.0003

0.0000

BS181A Nitronic 60

$\begin{array}{llllllll}\text { XG: } & 16.5 & 8.2 & 62.3 & 0.1 & 8.2 & 0.2 & 0.0 \\ \text { YC: } & 0.2280 & 0.0822 & 0.4647 & 0.0005 & 0.0336 & 0.0008 & 0.0000 \\ \text { YM: } & 0.2386 & 0.0729 & 0.3977 & 0.0000 & 0.0253 & 0.0000 & 0.0000 \\ \text { BS193 } & 18 \mathrm{Cr}-12 \mathrm{Mn} & & & & & \\ \text { XG: } & 18.5 & 12.1 & 66.0 & 0.0 & 1.8 & 0.1 & 0.0 \\ \text { YC } & 0.2501 & 0.1175 & 0.4599 & 0.0002 & 0.0070 & 0.0004 & 0.0000 \\ \text { YM: } & 0.2795 & 0.1197 & 0.3965 & 0.0000 & 0.0043 & 0.0000 & 0.0000\end{array}$

BS182 17Cr-15Mn

$\begin{array}{llllllll}\text { XG: } & 16.7 & 15.1 & 65.0 & 0.0 & 1.1 & 0.6 & 0.0 \\ \text { YC: } & 0.2223 & 0.1437 & 0.4639 & 0.0002 & 0.0043 & 0.0023 & 0.0000 \\ \text { YM: } & 0.2149 & 0.1524 & 0.4243 & 0.0000 & 0.0017 & 0.0005 & 0.0000\end{array}$ BS200A Nickel 200

$\begin{array}{llllllll}\text { XG: } & 0.0 & 0.2 & 0.1 & 0.1 & 99.5 & 0.0 & 0.0\end{array}$

YC. $\quad \begin{array}{llllllll}0.0000 & 0.0027 & 0.0016 & 0.0006 & 0.9921 & 0.0000 & 0.0000\end{array}$

$\begin{array}{lllllllll}\text { YM: } & & 0.0073 & 0.0073 & 0.0071 & 0.0149 & 0.9942 & 0.0000 & 0.0012\end{array}$

BS400C Monel 400

$\begin{array}{llllllll}\text { XG. } & 0.5 & 1.0 & 1.6 & 0.1 & 64.6 & 31.7 & 0.0\end{array}$

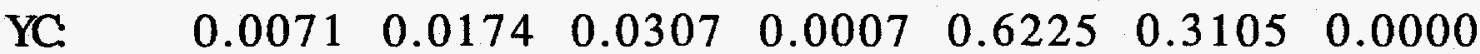

$\begin{array}{llllllll}\text { YM: } & 0.0130 & 0.0359 & 0.0462 & 0.0115 & 0.6209 & 0.2947 & 0.0000\end{array}$

BS500D Monel K500

$\begin{array}{llllllll}\mathrm{XG} & 0.2 & 0.7 & 0.7 & 0.0 & 64.9 & 29.7 & 0.0\end{array}$

YC. $\quad \begin{array}{llllllll}0.0032 & 0.0120 & 0.0147 & 0.0005 & 0.6579 & 0.3064 & 0.0000\end{array}$

YM: $\quad \begin{array}{llllllll}0.0089 & 0.0282 & 0.0211 & 0.0145 & 0.6565 & 0.2843 & 0.0000\end{array}$

BS600C Inconel 600

$\begin{array}{llllllll}\text { XG: } & 15.6 & 0.5 & 9.3 & 0.0 & 73.6 & 0.1 & 0.0\end{array}$

YC: $\quad \begin{array}{llllllll}0.1880 & 0.0064 & 0.0972 & 0.0003 & 0.5207 & 0.0004 & 0.0000\end{array}$

$\begin{array}{lllllllll}\text { YM: } & 0.1926 & 0.0084 & 0.1047 & 0.0069 & 0.4756 & 0.0000 & 0.0005\end{array}$

BS625A Inconel 625

$\begin{array}{llllllll}\text { XG. } & 21.7: & 0.1 & 3.1 & 0.1 & 61.4 & 0.1 & 0.0\end{array}$

YC. $\quad \begin{array}{llllllll} & 0.2026 & 0.0007 & 0.0251 & 0.0005 & 0.4351 & 0.0005 & 0.0000\end{array}$ 
YM: $\quad \begin{array}{llllllll}0.2061 & 0.0034 & 0.0305 & 0.0060 & 0.3870 & 0.0004 & 0.0000\end{array}$ BS690 Inconel 690

$\begin{array}{llllllll}\text { XG: } & 30.1 & 0.2 & 9.5 & 0.1 & 58.5 & 0.3 & 0.0 \\ \text { YC: } & 0.3293 & 0.0023 & 0.0708 & 0.0005 & 0.3644 & 0.0019 & 0.0000 \\ \text { YM: } & 0.3422 & 0.0000 & 0.0639 & 0.0088 & 0.3118 & 0.0046 & 0.0006\end{array}$ BS800 Incoloy 800

$\begin{array}{llllllll}\text { XG. } & 19.9 & 0.8 & 45.8 & 0.1 & 31.4 & 0.3 & 0.0\end{array}$

YC: $\quad \begin{array}{llllllll}0.2344 & 0.0080 & 0.3372 & 0.0004 & 0.1480 & 0.0016 & 0.0000\end{array}$

$\begin{array}{lllllllll}\text { YM: } \quad & 0.2605 & 0.0065 & 0.3263 & 0.0078 & 0.1196 & 0.0016 & 0.0000\end{array}$

BS718A Inconel 718

$\begin{array}{llllllll}\text { XG. } & 18.2 & 0.1 & 19.2 & 0.3 & 52.0 & 0.1 & 0.0\end{array}$

$\begin{array}{lllllllll}\text { YC } & & 0.1777 & 0.0008 & 0.1555 & 0.0023 & 0.3172 & 0.0004 & 0.0000\end{array}$

YM: $\quad \begin{array}{lllllllll}0.1832 & 0.0015 & 0.1419 & 0.0060 & 0.2529 & -.0001 & 0.0000\end{array}$

BS750A Inconel $\times 750$

$\begin{array}{llllllll}\text { XG: } & 15.7 & 0.1 & 7.1 & 0.3 & 71.9 & 0.0 & 0.0\end{array}$

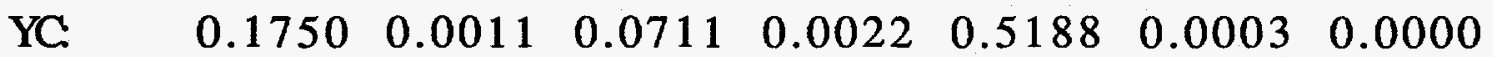

$\begin{array}{lllllllll}\text { YM: } & 0.1767 & 0.0086 & 0.0785 & 0.0110 & 0.4539 & 0.0007 & 0.0000\end{array}$

BSH-1B Hastelloy B

XG: $\quad \begin{array}{lllllll}\text { X.0 } & 0.8 & 1.0 & 0.0 & 71.4 & 0.0 & 0.0\end{array}$

YC $\quad \begin{array}{llllllll}0.0000 & 0.0081 & 0.0119 & 0.0000 & 0.6224 & 0.0000 & 0.0000\end{array}$

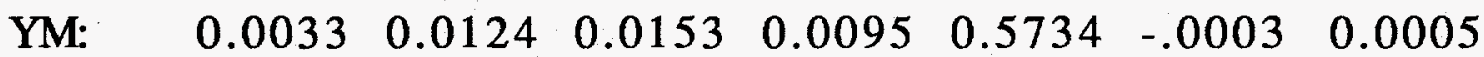

BSH-2B Hastelloy C-276

$\begin{array}{llllllll}\text { XG: } & 15.4 & 0.6 & 6.5 & 0.4 & 56.8 & 0.1 & 0.0\end{array}$

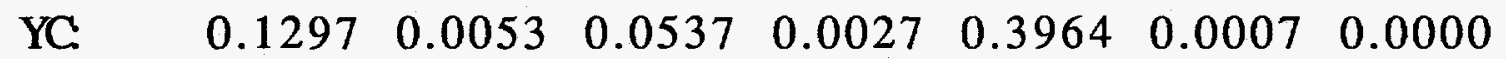

$\begin{array}{lllllllll}\text { YM: } & 0.1284 & 0.0124 & 0.0514 & 0.0103 & 0.3605 & 0.0022 & 0.0000\end{array}$

BSH-3B Hastelloy X

$\begin{array}{llllllll}\text { XG: } & 22.2 & 0.1 & 19.9 & 2.0 & 44.9 & 0.3 & 0.0\end{array}$

YC. $\quad \begin{array}{llllllll}0.2121 & 0.0011 & 0.1460 & 0.0132 & 0.2637 & 0.0017 & 0.0000\end{array}$

$\begin{array}{lllllllll}\text { YM: } & & 0.2351 & 0.0000 & 0.1572 & 0.0137 & 0.2229 & 0.0042 & 0.0000\end{array}$

BSH-6A Hastelloy C-22

$\begin{array}{llllllll}\text { XG. } & 21.4 & 0.3 & 4.3 & 1.1 & 55.8 & 0.1 & 0.0\end{array}$

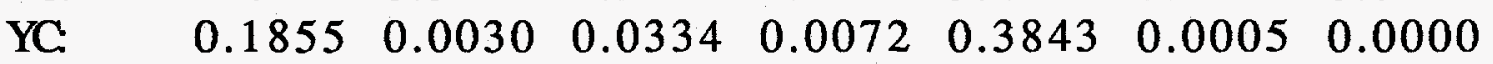

$\begin{array}{lllllllll}\text { YM: } & 0.1901 & 0.0000 & 0.0357 & 0.0073 & 0.3231 & -.0006 & 0.0000\end{array}$

BSH-8 Hastelloy G-30

$\begin{array}{llllllll}X G & 29.4 & 1.1 & 14.6 & 2.6 & 41.8 & 1.7\end{array}$

YC. $\quad \begin{array}{llllllll}0.2762 & 0.0109 & 0.0967 & 0.0159 & 0.2434 & 0.0099 & 0.0000\end{array}$

YM: $\quad \begin{array}{llllllll}0.2940 & 0.0125 & 0.0837 & 0.0176 & 0.2121 & 0.0091 & 0.0009\end{array}$

BS197A RA 333

$\begin{array}{llllllll}\text { XG. } & 25.1 & 1.6 & 18.1 & 3.1 & 44.4 & 0.1 & 0.0\end{array}$

YC. $\quad \begin{array}{llllllll}0.2515 & 0.0161 & 0.1298 & 0.0198 & 0.2593 & 0.0007 & 0.0000\end{array}$

YM: $\quad \begin{array}{lllllllll}0.2638 & 0.0170 & 0.1139 & 0.0199 & 0.2087 & -.0004 & 0.0000\end{array}$

BS199A Waspaloy

$\begin{array}{llllllll}\text { XG. } & 19.2 & 0.0 & 1.0 & 13.5 & 57.8 & 0.0 & 0.0\end{array}$ 


$\begin{array}{llllllll}\text { YC } & 0.2038 & 0.0002 & 0.0093 & 0.0932 & 0.4393 & 0.0001 & 0.0000 \\ \text { YM: } & 0.1883 & 0.0059 & 0.0175 & 0.0885 & 0.3751 & 0.0000 & 0.0007 \\ \text { BS191 } & 16 \mathrm{Cr}-6 \mathrm{Mn}-4 \mathrm{Si} & & & & & \\ \text { XG: } & 16.3 & 5.7 & 67.7 & 0.1 & 5.3 & 0.3 & 0.0 \\ \text { YC } & 0.2305 & 0.0571 & 0.5006 & 0.0008 & 0.0215 & 0.0014 & 0.0000 \\ \text { YM: } & 0.2199 & 0.0662 & 0.4223 & 0.0000 & 0.0152 & 0.0012 & 0.0000 \\ \text { MANGANIN } & \text { Cu 86/Mnn } 12 / \mathrm{Ni2} & & & & \\ \text { XG: } & 0.0 & 12.0 & 0.0 & 0.0 & 2.0 & 86.0 & 0.0 \\ \text { YC: } & 0.0000 & 0.1756 & 0.0000 & 0.0000 & 0.0192 & 0.7300 & 0.0000 \\ \text { YM: } & 0.0101 & 0.1735 & 0.0183 & 0.0037 & 0.0370 & 0.6680 & 0.0000 \\ \text { NIAG } & \text { Cu62/Ni18/Zn20 } & & & & & \\ \text { XG: } & 0.0 & 0.0 & 0.0 & 0.0 & 18.0 & 62.0 & 20.0 \\ \text { YC: } & 0.0000 & 0.0000 & 0.0000 & 0.0000 & 0.2292 & 0.6183 & 0.1598 \\ \text { YM: } & 0.0119 & 0.0065 & 0.0169 & 0.0021 & 0.2496 & 0.6339 & 0.1045 \\ \text { CONSTANT Cu55/Ni45 } & & & & & \\ \text { XG: } & 0.0 & 0.0 & 0.0 & 0.0 & 45.0 & 55.0 & 0.0 \\ \text { YC: } & 0.0000 & 0.0000 & 0.0000 & 0.0000 & 0.4705 & 0.5617 & 0.0000 \\ \text { YM: } & 0.0069 & 0.0349 & 0.0216 & 0.0057 & 0.4382 & 0.5460 & 0.0000 \\ \text { CU63ZN37 } & \text { Brass } & & & & & \\ \text { XG: } & 0.0 & 0.0 & 0.0 & 0.0 & 0.0 & 63.0 & 37.0 \\ \text { YC: } & 0.0000 & 0.0000 & 0.0000 & 0.0000 & 0.0000 & 0.6206 & 0.4006 \\ \text { YM: } & 0.0045 & 0.0039 & 0.0118 & 0.0052 & 0.0141 & 0.6228 & 0.3660\end{array}$

Table III. Table of results for the analysis algorithm described in this report applied to the 72 alloys used as the standard library. Each alloy was excluded from the library during its analysis. Only the major constituents are shown. The alloy name and grade are given followed by the measured intensity, the composition from the algorithm, and the known composition from the manufacturer. $Y U$ is the measured intensity, $\mathrm{XU}$ the measured composition, and $\mathrm{XG}$ the known composition.

$\begin{array}{llllllll} & : \mathrm{Cr} & \mathrm{Mn} & \mathrm{Fe} & \mathrm{Co} & \mathrm{Ni} & \mathrm{Cu} & \mathrm{Zn} \\ \text { BS44 } & \mathrm{C}- & .5 \mathrm{Mo} & 4419 & & & & \\ \text { YU: } & 0.0116 & 0.0180 & 0.9946 & 0.0000 & 0.0028 & 0.0000 & 0.0000 \\ \text { XU: } & 0.5 & 0.5 & 96.2 & 0.0 & 0.5 & 0.0 & 0.0 \\ \text { XG: } & 0.1 & 0.6 & 97.9 & 0.0 & 0.1 & 0.2 & 0.0 \\ \text { BS45A } & 1.25 \mathrm{Cr}- & .5 \mathrm{Mo} & \mathrm{F}-1 & & & & \\ \text { YU: } & 0.0255 & 0.0166 & 0.9115 & 0.0058 & 0.0000 & 0.0000 & 0.0000 \\ \text { XU: } & 1.3 & 0.3 & 94.2 & 0.2 & 0.0 & 0.0 & 0.0 \\ \text { XG: } & 1.2 & 0.5 & 96.6 & 0.0 & 0.2 & 0.2 & 0.0\end{array}$

BS46A $2.25 \mathrm{Cr}-1 \mathrm{Mo}$ F-22 
$\begin{array}{llllllll}\text { YU: } & 0.0651 & 0.0314 & 0.8920 & 0.0027 & 0.0057 & 0.0000 & 0.0001 \\ \text { XU: } & 3.5 & 0.6 & 87.0 & 0.1 & 0.8 & 0.0 & 0.0 \\ \text { XG: } & 2.4 & 0.6 & 95.4 & 0.0 & 0.2 & 0.1 & 0.0\end{array}$

BS47A $5 \mathrm{Cr}-\quad .5 \mathrm{Mo} \quad \mathrm{F}-5$

$\begin{array}{lllllllll}\text { YU: } & \quad & 0.0896 & 0.0232 & 0.8830 & 0.0000 & 0.0007 & -.0005 & 0.0000\end{array}$

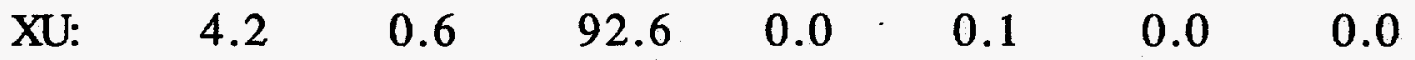

$\begin{array}{llllllll}\text { XG: } & 4.2 & 0.4 & 94.1 & 0.0 & 0.1 & 0.1 & 0.0\end{array}$

BS48A $9 \mathrm{Cr}-1 \mathrm{Mo} \quad \mathrm{F}-9$

YU: $\quad 0.1551 \quad 0.0205$

$\begin{array}{lllll}0.6849 & 0.0000 & 0.0052 & 0.0000 & 0.0000\end{array}$

$\mathrm{XG}$. $\quad 8.8$

0.7

86.3

0.0

1.1

0.0

0.0

BS150 $182 \mathrm{FM}$

YU: $\quad 0.2706$

$\mathrm{XU}:$

19.5

0.4

88.5

0.0

0.3

0.1

0.0

XG:

18.6

0.0129

0.4591

$\begin{array}{llll}0.0000 & -.0002 & -.0002\end{array}$

0.0000

$\begin{array}{ll}77.2 & 0.0\end{array}$

0.0

0.0

0.0

BS151 416

1.7

76.5

0.0

0.2

0.0

0.0

YU: $\quad 0.2140$

XU:

12.8

$\mathrm{Se}$

$\mathrm{XG}: \quad 13.2$

0.0143

$\begin{array}{ll}0.6033 & 0.0033\end{array}$

$\begin{array}{lll}0.0000 & -.0004\end{array}$

0.0000

BS410A 410

YU: $\quad 0.2223$

0.4

85.9

0.2

0.0

0.0

0.0

85.1

0.0

0.2

0.1

0.0

XU: $\quad 13.3$

0.0077

0.5690

XG: $\quad 13.2$

0.3

86.2

0.0084

0.0007

0.0000

0.1

0.0

0.0000

BS90F 416

YU: $\quad 0.2193$

0.5

85.3

0.0

0.2

0.0

0.0

0.0

XU:

14.1

0.0234

$0.5944 \quad 0.0000$

0.0005

0.0000

0.0000

$\begin{array}{ll}X G & 13.0\end{array}$

BS95A 450

YU: $\quad 0.2327$

0.7

81.7

0.1

0.0

0.0

$84.7 \quad 0.0$

0.3

0.1

0.0

$\mathrm{XU}$ : 16.3

0.0117

$\begin{array}{ll}0.5078 & 0.0000\end{array}$

XG: $\quad 14.7$

$0.5 \quad 74.2$

0.0

0.0183

0.0027

5.8

1.1

1.5

0.0

74.8

0.1

6.4

1.5

BS97 422

YU: $\quad 0.177$

$\mathrm{XU}: \quad 11.2$

0.0204

0.6076

0.0050

0.0036

0.0000

0.0

XG. $\quad 11.8$

BS98 420 .

YU: $\quad 0.2254$

0.5

82.4

0.2

2.0

0.0

0.0000

0.7

83.7

0.0

0.8

0.1

0.0

0.0

XU: 13.7

0.0121

$\begin{array}{lll}0.5637 & 0.0033\end{array}$

0.0000

0.0000

0.0000

XG: $\quad 13.3$

0.7

83.5

0.3

0.0

0.0

0.0

BS152 420F

YU:

0.2089

0.5

84.6

0.0

0.2

0.1

0.0

$\mathrm{XU}$ :

12.9

0.0129

$\begin{array}{ll}0.5511 & 0.0009\end{array}$

0.0000

0.0000 86.5

0.0

0.0

0.0

0.0000

$\mathrm{XG}$. 13.4

0.4

84.8

0.0

0.1

0.1

0.0 
BS91E 430

$\begin{array}{llllllll}\text { YU: } & 0.2424 & 0.0114 & 0.5208 & 0.0024 & 0.0000 & -.0003 & 0.0000\end{array}$

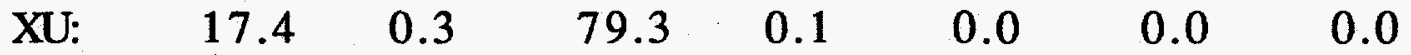

$\begin{array}{llllllll}\text { XG: } & 16.6 & 0.4 & 82.0 & 0.0 & 0.2 & 0.1 & 0.0\end{array}$

BS153 430F

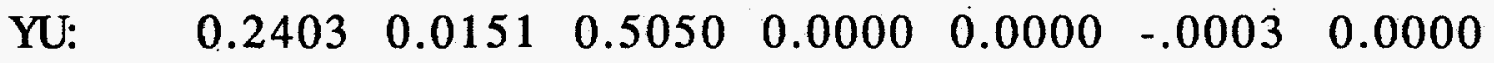

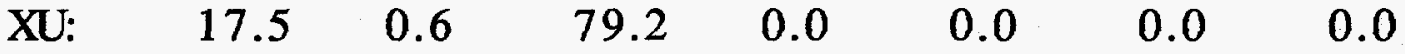

$\begin{array}{llllllll}\text { XG: } & 17.4 & 0.4 & 80.8 & 0.0 & 0.1 & 0.1 & 0.0\end{array}$

BS92B 431

YU: $\quad 0.2292$

XU: $\quad \begin{array}{llll}16.4 & 0.7 & 79.2 & 0.7\end{array}$

$\begin{array}{llllllll}\text { XG: } & 15.9 & 0.4 & 80.4 & 0.0 & 2.1 & 0.1 & 0.0\end{array}$

BS93E 440C

YU: $\quad 0.2578$

XU: $\quad 18.9$

17.3

BS155 440F

YU. $\quad 0.2399$

XU: $\quad 17.0$

0.0122

$\begin{array}{lll}0.0079 & 0.5006\end{array}$

0.2

78.9

0.0000

$0.0009 \quad 0.0000$

$0.5 \quad 78.8$

0.0

0.1

0.0

0.4

0.1

0.0

0.0

0.5

0.5168

0.0000

0.0000

0.0000 $80.6 \quad 0.0$

0.0

0.0

0.0000

XG. $\quad 16.6$

0.4

80.7

0.0

0.1

0.0

0.0

BS156 440F Se

YU: $\quad 0.2575$

XU: $\quad 17.7$

0.0256

0.5292

0.9

79.2

0.0000

0.0000

$0.0001 \quad 0.0000$

XG. $\quad 16.9$

1.1

79.1

0.0

0.0

0.0

0.0

BS94C 446

YU: $\quad 0.3645$

0.0027

0.0

0.4

0.1

0.0

XU: $\quad 26.7$

0.2

0.38910 .0000

0.0017

0.0000

0.0000

XG. 25.9

0.4

69.8

0.0

0.5

0.0

0.0

BS825A : Incoloy 825

YU:

$\begin{array}{lll}0.2296 & 0.0137\end{array}$

72.0

0.0

0.4

0.1

0.0

XU:

20.2

1.5

$\begin{array}{lll}0.2077 & 0.0069\end{array}$

0.1605

0.0094

0.0000

XG: $\quad 21.4$

0.6

32.4

0.3

37.8

2.3

0.0

BS96A 455

YU: $\quad 0.1699 \quad 0.0064$

$\mathrm{XU}$ :

$$
11.3
$$

0.2

30.2

0.2

$39.8 \quad 2.3$

0.0

XG. $\quad 11.6$

BS203MN 203

YU: $\quad 0.2498 \quad 0.0659$

XU:

0.54330 .0026

0.0237

0.0061

0.0000 69.3

0.1

17.7

0.6

0.0

76.2

0.0

8.4

2.1

0.0

XG: 17.5

7.3

0.4623

0.0000

0.0105

0.0053

0.0000 67.7

0.0

3.3

1.6

0.0

BS80F 303

YU:

$0.2410 \quad 0.0157$

68.7

0.1

5.5

1.9

0.0

XU:

17.1

1.7

0.4540

0.0000

0.0259

0.0013

0.2

0.0000

69.3

0.0

9.9

0.2

0.0 
$\mathrm{XG}$ :

$17.1 \quad 1.8$

70.2

0.2

8.6

0.4

0.0

BSCA304 304

YU: $\quad 0.2601$

$\mathrm{XU}:$

18.9

0.0102

0.4544

0.0014

$\begin{array}{lll}0.0182 & 0.0038 & 0.0000\end{array}$

XG:

$18.3 \quad 1.1$

69.3

0.1

5.7

1.1

0.0

BS81G 304L

YU: $\quad 0.2435$

$\mathrm{XU}:$

\section{2}

0.0212

70.1

0.2

8.6

0.3

0.0

$\mathrm{XG}:$

$$
18.6
$$

2.4

0.4250

0.0049

0.0251

0.0022

0.0000

BS82D 309

YU: $\quad 0.3100$

$\mathrm{XU}: \quad 23.4$

1.7

68.3

0.4

8.2

0.7

0.0

$\begin{array}{ll}68.9 & 0.3\end{array}$

8.2

0.5

0.0

XG. $\quad 22.4$

BS83H 310

$\begin{array}{llllllll}\text { YU: } & 0.3271 & 0.0130 & 0.2949 & 0.0042 & 0.0619 & 0.0000 & 0.0000 \\ \text { XU: } & 26.2 & 1.0 & 55.0 & 0.0 & 17.7 & 0.0 & 0.0 \\ \text { XG: } & 24.2 & 1.5 & 52.6 & 0.2 & 20.0 & 0.2 & 0.0\end{array}$

XG: 24.2

BS316B 316

YU: $\quad 0.2289$

XU:

$$
17.0
$$

0.0252

$0.3609 \quad 0.0054$

2.1

60.4

0.4

0.0485

0.0002

0.0000

$\mathrm{XG}$ :

$$
16.2
$$

0.0217

60.3

0.0

11.5

0.0

0.0

14.1

0.2

0.0

BS84J $316 \mathrm{~L}$

YU: $\quad 0.2307$

XU:

$$
17.0
$$

1.5

52.6

$\mathrm{XG}$ :

$$
17.1
$$

1.3

$0.4596 \quad 0.0000$

68.5

0.0

0.0287

0.0010

9.0

0.6

0.0000

69.3

0.2

10.1

0.4

0.0

0.0

BS317L 317L

YU: $\quad 0.2246 \quad 0.0218$

$\mathrm{XU}:$

18.8

0.0221

$\begin{array}{lll}0.4460 & 0.0074\end{array}$

0.0329

0.0008

0.0000

65.0

0.5

10.5

0.3

0.0

67.4

0.2

10.3

0.5

0.0

$\begin{array}{ll}X G: & 18.2\end{array}$

BS321A 321

YU: $\quad 0.2184 \quad 0.0225$

XU: $\quad 15.9$

1.8

0.3899

0.0000

0.0429

$-.0001$

0.0000

$\mathrm{XG}$ :

17.2

2.6

63.3

0.0

12.9

0.0

0.0

62.8

0.1

13.5

0.2

0.0

BS86E $\quad 330$

YU: $\quad 0.2204 \quad 0.0171$

$\mathrm{XU}$ :

18.2

2.2

$\begin{array}{ll}0.4415 & 0.0013\end{array}$

0.0237

0.0019

0.0000

$\mathrm{XG}$. $18.5 \quad 1.4$

71.1

0.0

9.8

0.3

0.0

70.3

0.2

9.4

0.3

0.0

BS347A 347

YU: $\quad 0.2471$

XU:

$$
17.4
$$

0.0226

0.3011

0.0036

0.1263

0.0044

0.0000

43.6

0.0

34.5

0.9

0.0

42.7

$0.1 \quad 35.3$

0.2

0.0

XG:

BS192

17.4

2.5

0.4574

0.0000

0.0268

$-.0007$

0.0000

70.9

0.0

9.0

0.0

0.0

69.6

0.1

9.2

0.3

0.0

YU:

\section{2301}

0.0074

0.4545

0.0038

0.0172

0.0023

0.0000 
$\begin{array}{llllllll}\text { XU: } & 17.2 & 0.9 & 72.8 & 0.3 & 5.9 & 0.8 & 0.0 \\ \text { XG: } & 16.4 & 0.8 & 72.6 & 0.1 & 7.1 & 0.4 & 0.0\end{array}$

BS318 2205

YU: $\quad 0.3032 \quad 0.0160$

$\begin{array}{lll}6 & 0.3989 & 0.0000\end{array}$

$\begin{array}{ll}0.0221 & 0.0000\end{array}$

$\mathrm{XG}$.

22.8

2.1

67.2

0.0

2.2

0.0

0.0000

BS88G 17-4PH

YU: $\quad 0.2204$

XU:

15.7

1.4

66.4

0.1

5.6

0.2

0.0

XG. $\quad 15.7$

0.0094

$\begin{array}{ll}0.4927 & 0.0009\end{array}$

0.0130

0.0097

0.0000

BS185A $15-5 \mathrm{PH}$

YU: $\quad 0.2235 \quad 0.0136$

XU:

$$
15.6
$$

0.5

76.9

0.0

3.8

1.1

0.0

$\mathrm{XG}$

14.5

0.5

74.4

0.1

4.3

4.0

0.0

BS263 Alloy 263

YU: $\quad 0.2130 \quad 0.0000$

XU:

21.5

0.0

0.5305

0.0016

0.0090

0.0127

0.0000

XG. $\begin{array}{ll}19.8 & 0.4\end{array}$

78.7

0.0

1.0

1.4

0.0

$76.0 \quad 0.0$

4.4

3.4

0.0

BS189 N08367

YU: $\quad 0.2401 \quad 0.0061$

XU:

0.2401

0.9

0.0079

0.1219

0.5

18.4

0.3441

0.0000

0.0000

$\mathrm{XG}$ :

$20.6 \quad 0.3$

BS179A

YU:

Alloy

0.5

$20.0 \quad 50.3$

0.0

0.0

0.0

0.0

$\quad 0.31320 .0083$

$\begin{array}{lll}\mathrm{XU}: & 26.1 & 0.8 \\ \mathrm{XG}: & 25.5 & 1.0\end{array}$

$\begin{array}{lllll}0.2941 & 0.0040 & 0.0873 & 0.0024 & 0.0000 \\ 48.3 & 0.0 & 25.9 & 0.5 & 0.0 \\ 47.8 & 0.0 & 23.8 & 0.6 & 0.0\end{array}$

BS184A PH13-8 Mo

YU: $\quad 0.1700 \quad 0.0134$

XU: $\quad \begin{array}{ll}12.2 & 0.4\end{array}$

0.5000

0.3337

63.4

0.0056

0.0166

$\begin{array}{ll}0.0051 & 0.0000\end{array}$

XG:

12.7

0.1

61.1

0.5

4.3

0.6

0.0

0.6

5.8

1.9

0.0

BS183 Greek Ascoloy

YU:

XU:

0.1751

0.0117

68.5

0.0012

0.0232

0.0001

17.6

0.0

0.0000

75.4

0.0

8.3

0.0

0.0

0.0

$\mathrm{XG}$ :

12.9

0.1

0.5210

0.0000

0.0021

$0.0000 \quad 0.0000$

$\begin{array}{ll}82.5 & 0.0\end{array}$

0.8

0.0

0.0

BS186A Invar 36

YU: $\quad \begin{array}{lll}0.0103 & 0.0169\end{array}$

$\mathrm{XU}$ :

0.6

0.5

81.0

0.0

2.0

0.1

0.0

$\mathrm{XG}$.

0.2

0.7

0.7479

0.0047

78.2

0.0

0.1346

0.0009

0.0000

BS187A Carp. 20Cb3

YU:

$\begin{array}{lll}0.2632 & 0.0051\end{array}$

63.0

0.0

19.5

0.1

0.0

35.9

0.0

0.0

XU:

21.6

0.6

0.2762

0.0093

0.1374

0.0122

0.0000

XG: 19.8 0.5 39.6

0.1

33.6

2.2

0.0

BS188A A-286

0.3

33.1

3.1

0.0 
$\begin{array}{llllllll}\text { YU: } & 0.1746 & 0.0037 & 0.3953 & 0.0025 & 0.0842 & 0.0008 & 0.0000 \\ \text { XU: } & 14.9 & 0.2 & 56.3 & 0.1 & 21.8 & 0.4 & 0.0 \\ \text { XG: } & 14.0 & 0.1 & 56.9 & 0.2 & 24.6 & 0.1 & 0.0\end{array}$

BS190 Nitronic 40

YU: $\quad \begin{array}{llllllll}0.2785 & 0.1006 & 0.3876 & 0.0000 & 0.0196 & 0.0000 & 0.0000\end{array}$

$\begin{array}{llllllll}\mathrm{XU}: & 18.5 & 9.9 & 63.1 & 0.0 & 7.9 & 0.0 & 0.0\end{array}$

$\begin{array}{llllllll}\text { XG. } & 19.6 & 9.7 & 62.8 & 0.0 & 6.7 & 0.1 & 0.0\end{array}$

BS180A Nitronic 50

YU: $\quad 0.2684 \quad 0.0486$

$\mathrm{XU}: \quad 21.6 \quad 3.9$

$\begin{array}{llll}0.3317 & 0.0000 & 0.0410 & 0.0000\end{array}$

XG: $\quad 21.1 \quad 5.1$

BS181A Nitronic 60

YU: $\quad \begin{array}{llll}0.2386 & 0.0729\end{array}$

XU: $\quad 18.6 \quad 6.3$

$\begin{array}{lllll}60.6 & 0.0 & 13.0 & 0.0 & 0.0\end{array}$

$\begin{array}{llll}57.4 & 0.0 & 13.2 & 0.1\end{array}$

0.0

XG. $\quad 16.5 \quad 8.2$

BS193 18Cr-12Mn

YU: $\quad 0.2795 \quad 0.1197$

$\begin{array}{llll}0.3977 & 0.0000 & 0.0253\end{array}$

$\begin{array}{ll}66.0 & 0.0\end{array}$

8.6

0.0000

0.0000

62.3

0.1

8.2

0.0

0.0

XU:

19.6

12.0

0.3965

$\begin{array}{llll}0.0000 & 0.0043 & 0.0000 & 0.0000 \\ 0.0 & 1.6 & 0.0 & 0.0 \\ 0.0 & 1.8 & 0.1 & 0.0\end{array}$

$\begin{array}{lll}X G . & 18.5 & 12.1\end{array}$

BS 182 17Cr-15Mn

YU: $\quad 0.2149 \quad 0.1524$

66.5

66.0

16.3

0.4243

0.0000

$\mathrm{XU}$ :

14.3

15.1

68.1

0.0

0.0017

$\mathrm{XG}$ : 16.7

65.0

0.0

0.7

0.0005

0.0000

BS200A Nickel 200

YU: $\quad 0.0073 \quad 0.0073$

$\mathrm{XU}$ :

0.2

0.2

0.0071

1.1

0.1

0.0

$\mathrm{XG}$ :

0.0

0.2

0.2

0.0149

0.9942

0.6

0.0

BS400C Monel 400

YU:

0.0130

0.0359

0.1

0.0

98.1

0.0000

0.0012

XU:

0.3

0.9

0.0462

0.1

99.5

0.0

0.1

XG:

0.5

1.0

1.7

0.0115

0.6209

0.0

0.0

BS500D Monel K500

YU: $\quad 0.0089 \quad 0.0282$

1.6

0.0

62.8

0.2947

0.0000

0.1

64.6

$\begin{array}{ll}31.6 & 0.0\end{array}$

$31.7 \quad 0.0$

$\mathrm{XU}$ :

0.3

0.8

0.0211

0.0145

0.6565

0.2843

0.0000

$X G$ :

0.2

0.7

0.7

0.1

66.1

29.6

0.0

BS600C Inconel 600

YU: $\quad 0.1926 \quad 0.0084$

$\mathrm{XU}:$

15.8

0.1

0.7

0.0

64.9

29.7

0.0

XG: $\quad 15.6 \quad 0.5$

BS625A Inconel 625

$\begin{array}{lll}\text { YU: } & 0.2061 & 0.0034\end{array}$

XU:

20.2

0.2

0.1047

0.0069

0.4756

$\begin{array}{lll}0.0000 & 0.0005\end{array}$

8.7

0.2

73.1

0.0

0.1

9.3

0.0

73.6

0.1

0.0

$\mathrm{XG}$ : 21.7

0.1

0.0305

0.0060

0.3870

0.0004

0.0000

3.2

0.9

63.6

0.0

0.0

0.1

61.4

0.1

0.0 
BS690 Inconel 690

YU: $\quad 0.3422 \quad 0.0000$

XU:

30.0

0.0

$\begin{array}{lll}0.0639 & 0.0088\end{array}$

0.3118

0.0046

0.0006

$\mathrm{XG}$. 30.1

0.2

9.6

1.3

57.5

0.8

0.1

BS800 Incoloy 800

YU:

$0.2605 \quad 0.0065$

9.5

$0.1 \quad 58.5$

0.3

0.0

$\mathrm{XU}:$

20.5

0.5

0.3263

0.0078

XG. $\quad 19.9$

0.8

45.0

0.2

0.1196

0.0016

0.0000

BS718A Inconel 718

YU: $\quad 0.1832 \quad 0.0015$

45.8

0.1

31.4

0.1

0.0

31.4

0.3

0.0

XU:

18.8

0.1

0.1419

0.0060

$0.2529-.0001$

0.0000

$\mathrm{XC}$

18.2

0.1

17.8

0.9

53.9

0.0

0.0

BS750A Inconel $\times 750$

19.2

0.3

52.0

0.1

0.0

YU: $\quad 0.1767 \quad 0.0086$

$\mathrm{XU}:$

15.6

0.6

0.0785

$\begin{array}{ll}0.0110 & 0.4539\end{array}$

XG: $\quad 15.7$

0.1

7.7

0.1

74.6

0.0007

0.0000

BSH-1B Hastelloy B

YU: $\quad \begin{array}{lll}0.0033 & 0.0124\end{array}$

7.1

0.3

71.9

0.0

0.0

0.0

XU:

0.3

0.5

0.0153

0.0095

$0.5734-.0003$

0.0005

$\mathrm{XG}$ :

0.0

0.8

0.3

0.1

69.8

0.0

0.0

BSH-2B Hastelloy C-276

YU: $\quad \begin{array}{llll}0.1284 & 0.0124 & 0.0514\end{array}$

$\mathrm{XU}$ :

14.4

1.0

5.2

0.0

71.4

0.0

0.0

XG. $\quad 15.4 \quad 0.6$

BSH-3B Hastelloy X

YU: $\quad 0.2351 \quad 0.0000$

XU: $\quad 22.1$

0.0

6.5

0.0103

0.3605

0.0022

0.0000

XG. $\quad 22.2$

0.1

1.4

55.0

0.2

0.0

0.4

56.8

0.1

0.0

BSH-6A Hastelloy C-22

YU:

$0.1901 \quad 0.0000$

0.1572

0.0137

22.9

1.7

0.2229

0.0042

43.0

0.7

44.9

0.3

0.0

2.0

0.0357

0.0073

$0.3231-.0006$

0.0000

XU:

23.2

0.0

4.4

0.1

58.7

0.0

0.0

XG: $\quad 21.4$

0.3

4.3

1.1

55.8

0.1

0.0

BSH-8 Hastelloy G-30

YU:

XU:

0.2940

0.0125

0.0837

0.0176

0.2121

0.0091

0.0009

$\mathrm{XG}$ :

29.1

1.2

14.1

2.8

43.3

0.8

0.1

29.4

1.1

14.6

2.6

41.8

1.7

0.0

BS197A RA 333

YU: $\quad 0.2638 \quad 0.0170$

XU:

$$
26.2
$$

1.5

0.1139

0.0199

0.2087

$-.0004$

0.0000

XG. $\quad 25.1$

1.6

19.3

2.9

44.0

0.0

0.0

BS199A Waspaloy

YU:

0.1883

0.0059

18.1

3.1

44.4

0.1

0.0

$\mathrm{XU}$ :

\begin{abstract}
17.8
0.5
\end{abstract}

0.0175

0.0885

0.3751

0.0000

0.0007 15.1

58.1

0.0

0.1 
$\begin{array}{llllllll}\text { XG. } & 19.2 & 0.0 & 1.0 & 13.5 & 57.8 & 0.0 & 0.0\end{array}$

BS191 16Cr-6Mn-4Si

$\begin{array}{llllllll}\text { YU: } & 0.2199 & 0.0662 & 0.4223 & 0.0000 & 0.0152 & 0.0012 & 0.0000 \\ \text { XU: } & 15.9 & 8.1 & 69.2 & 0.0 & 5.4 & 0.2 & 0.0 \\ \text { XG: } & 16.3 & 5.7 & 67.7 & 0.1 & 5.3 & 0.3 & 0.0\end{array}$ MANGANIN Cu86/Mn12/Ni2

YU: $\quad \begin{array}{llllllll}0.0101 & 0.1735 & 0.0183 & 0.0037 & 0.0370 & 0.6680 & 0.0000\end{array}$

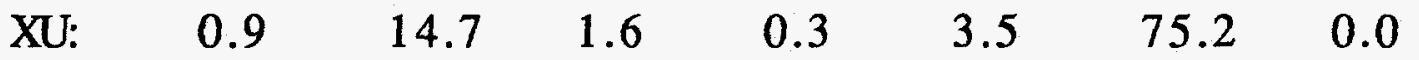

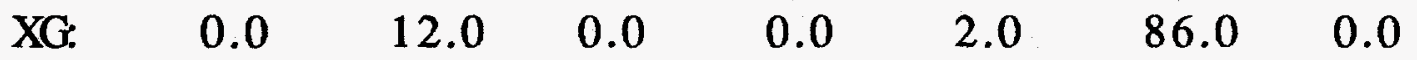

NIAG $\quad \mathrm{Cu} 62 / \mathrm{Ni} 18 / \mathrm{Zn} 20$

YU: $\quad \begin{array}{llllllll}0.0119 & 0.0065 & 0.0169 & 0.0021 & 0.2496 & 0.6339 & 0.1045\end{array}$

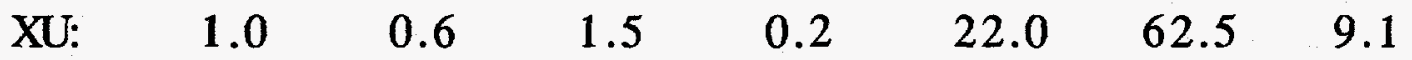

$\begin{array}{llllllll}\text { XG. } & 0.0 & 0.0 & 0.0 & 0.0 & 18.0 & 62.0 & 20.0\end{array}$

CONSTANT Cu55/Ni45

$\begin{array}{llllllll}\text { YU: } & 0.0069 & 0.0349 & 0.0216 & 0.0057 & 0.4382 & 0.5460 & 0.0000\end{array}$

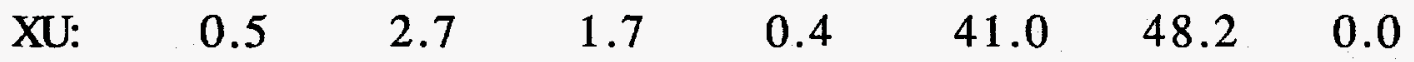

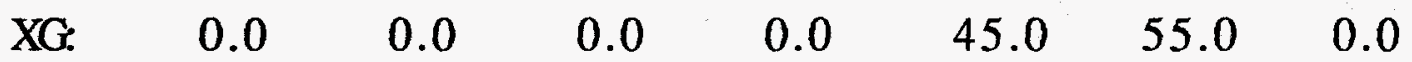

CU63ZN37 Brass

YU: $\quad \begin{array}{llllllll}0.0045 & 0.0039 & 0.0118 & 0.0052 & 0.0141 & 0.6228 & 0.3660\end{array}$

$\begin{array}{llllllll}\mathrm{XU}: & 0.4 & 0.3 & 1.0 & 0.4 & 0.6 & 55.7 & 39.7\end{array}$

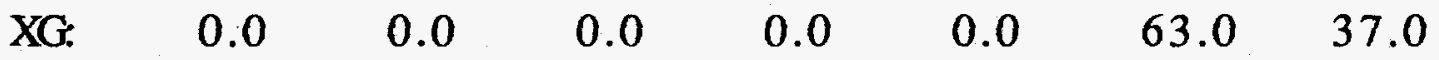

